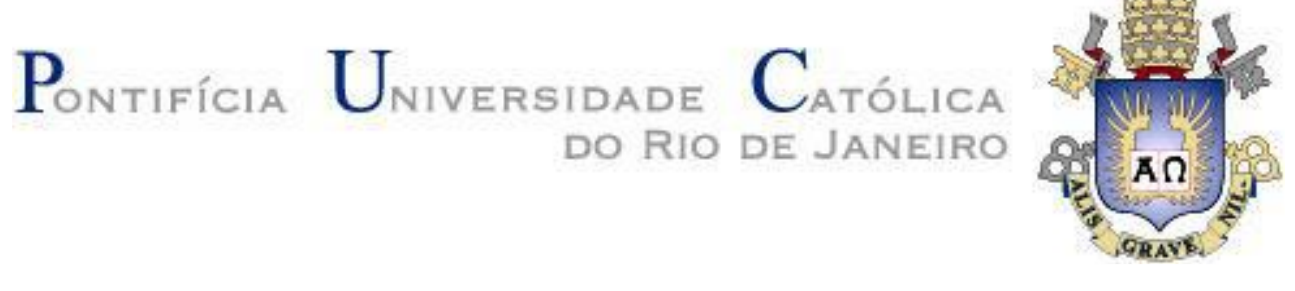

Joanna Ferreira Leusin

\title{
Clima familiar e problemas emocionais e Comportamentais em uma amostra de crianças do Rio de Janeiro
}

Dissertação de Mestrado

Dissertação apresentada como requisito parcial para obtenção do grau de Mestre pelo Programa de Pósgraduação em Psicologia Clínica do Departamento de Psicologia da PUC-Rio.



Rio de Janeiro

Março de 2017 


\title{
Joanna Ferreira Leusin
}

Clima familiar e problemas emocionais e comportamentais em uma amostra de crianças do Rio de Janeiro

Dissertação apresentada como requisito parcial para obtenção do grau de Mestre pelo Programa de Pós-Graduação em Psicologia (Psicologia Clínica) do Departamento de Psicologia do Centro de Teologia e Ciências Humanas da PUC-Rio. Aprovada pela Comissão Examinadora abaixo assinada.

\author{
Profa. Juliane Callegaro Borsa \\ Orientadora \\ Departamento de Psicologia - PUC Rio
}

Profa. Luciana Fontes Pessôa Departamento de Psicologia - PUC Rio

Profa. Mônica de Vasconcellos Dias

Departamento de Psicologia - UVA

Profa. Monah Winograd Coordenadora Setorial de Pós-Graduação e Pesquisa do Centro de Teologia e Ciências Humanas - PUC Rio

Rio de Janeiro, 29 de março de 2017. 
Todos os direitos reservados. É proibida a reprodução total ou parcial do trabalho sem autorização do autor, do orientador e da universidade.

\section{Joanna Ferreira Leusin}

Graduou-se em Psicologia na Pontifícia Universidade Católica do Rio Grande do Sul (PUCRS) em 2013. Cursou direito na PUCRS em 2005. Especializou-se em Terapia Familiar, de Casal e Individual abordagem sistêmico-integrado pelo INFAPA (Instituto da Família de Porto Alegre) em 2015. Trabalha com psicologia clínica desde 2013. Coordena um grupo de estudos sobre terapia familiar sistêmica desde 2015. Atua com projetos educacionais e sociais. Ministra palestras e participa de diferentes cursos.

Ficha Catalográfica

Leusin, Joanna Ferreira

Clima familiar e problemas emocionais e comportamentais em uma amostra de crianças do Rio de Janeiro / Joanna Ferreira Leusin; orientadora: Juliane Callegaro Borsa. - Rio de Janeiro PUC, Departamento de Psicologia, 2017.

v. 1,71 f. ; il. color. ; $30 \mathrm{~cm}$

1. Dissertação (mestrado) - Pontifícia Universidade Católica do Rio de Janeiro, Departamento de Psicologia, 2017.

Inclui referências bibliográficas.

1. Psicologia - Teses. 2. Família. 3. Clima familiar. 4. Problemas emocionais/comportamentais. 5. Crianças. I. Borsa, Juliane Callegaro. II. Pontifícia Universidade Católica do Rio de Janeiro. Departamento de Psicologia. III. Título.

CDD: 150 


\section{Agradecimentos}

À minha orientadora Juliane Callegaro Borsa, por estar ao meu lado durante todos os momentos do mestrado, me incentivando e inspirando com seu amor pela pesquisa científica, além de acreditar sempre na importância do desenvolvimento dos estudos empíricos.

Aos meus colegas do Grupo de Pesquisa APlab Pessoas e Contextos, Hugo Rosa, Natália Machado, Ilana Landim, Victor Hugo Costa, Bheatrix Bienemann e Fernanda Paveltchuk, por toda a ajuda que me dispensaram e por terem compartilhado comigo experiências e pensamentos enriquecedores.

Às bolsistas Mariana Doca, Paola Picorelli, Catherine Marques e Camila Araújo, pelo carinho, disposição, auxílio prestados nas coletas e também por estarem sempre disponíveis para ajudar e atentas em aprender, inspirando-me a buscar sempre o aprimoramento do meu trabalho.

A todos os meus colegas de mestrado, que me oportunizaram inúmeras discussões e trocas de ideias sobre as questões humanas tratadas no meu estudo, levando-me sempre a questionar e aprimorar meus pensamentos e argumentações.

Por último, mas não menos importante, o meu carinhoso agradecimento aos meus pais, que além de eternos incentivadores e investidores no meu desenvolvimento pessoal e profissional, são exemplos de apoio e amor incondicional. Sem a base que eles me deram, não finalizaria este, bem como muitos outros projetos de vida.

MUITO OBRIGADA! 


\section{Resumo}

Leusin, Joanna Ferreira; Borsa, Juliane Callegaro. Clima familiar e problemas emocionais e comportamentais em uma amostra de crianças do Rio de Janeiro Rio de Janeiro, 2017, 71p. Dissertação de Mestrado Departamento de Psicologia, Pontifícia Universidade Católica do Rio de Janeiro.

A literatura vem mostrando a forte influência da família e suas interações sobre o desenvolvimento das crianças. Este estudo tem como foco compreender a importância da família para o desenvolvimento infantil, especificamente a influência do clima familiar e das características familiares na ocorrência de problemas emocionais e comportamentais nas crianças. Para compreender a relação do clima familiar com os problemas emocionais e comportamentais das crianças, utilizou-se como aparato teórico a Abordagem Bioecológica do Desenvolvimento Humano e pesquisas semelhantes com o tema. Com esse intuito, investigou-se, em uma amostra de crianças da cidade do Rio de Janeiro, a relação entre o clima familiar, as características sociodemográficas da família e os problemas emocionais e comportamentais na infância. Participaram 237 famílias, dentre os respondentes, 168 mães, 39 pais e 30 cuidadores das crianças, entre 7 e 13 anos, matriculadas em escolas do Ensino Fundamental do Rio de Janeiro. Os dados foram coletados por meio do Inventário de Clima Familiar (ICF), do Child Behavior Checklist (CBCL 6/18), e de um questionário sociodemográfico. O clima familiar apresentou associação com renda familiar, saúde mental e escolaridade dos pais. Correlações de Pearson e regressões lineares múltiplas indicaram associação negativa entre apoio e coesão familiar e problemas emocionais/comportamentais infantis. Além disso, conflito e hierarquia relacionaram-se positivamente com estes problemas. Os resultados apontam para importância dos processos proximais, em especial do clima familiar, como fatores protetivos para o desenvolvimento infantil.

\section{Palavras-chave}

Família; clima familiar; problemas emocionais/comportamentais; crianças. 


\section{Abstract}

Leusin, Joanna Ferreira; Borsa, Juliane Callegaro (Advisor). Family climate and emotional and behavioral problems in a sample of children from Rio de Janeiro. Rio de Janeiro, 2017, 71p. Dissertação de Mestrado - Departamento de Psicologia, Pontifícia Universidade Católica do Rio de Janeiro.

Literature has been showing the family's strong influence and its interactions over children's development. This study has focused on comprehending the importance of family to children's development, specifically the influence of family climate and family characteristics in occurrence of emotional and behavioral problems in children. To comprehend the relation between family climate and emotional and behavioral problems in children, the Bioecological Approach to Development was used as theoretical apparatus, so as similar researches about the theme. With this purpose, a sample of children from Rio de Janeiro was investigated surrounding the relation between family climate, the family's sociodemographic characteristics and emotional and behavioral problems during childhood. Within the respondents of the 237 families who participated, 168 were mothers, 39 fathers and 30 caretakers for children, between 7 and 13 years old, registered in elementary schools in Rio de Janeiro. Data were collected through the Family-Climate Inventory, the Child Behavior Checklist and a socio-demographic questionnaire. The family climate had association with the family income, mental health and educational level of parents. Pearson's correlations and multiple linear regressions indicated a negative association between family support and cohesion and children's emotional/behavioral problems. Thus, conflict and family hierarchy were positively association with these problems. The results show the importance of the proximal processes, and especially the family climate, as an important source of protection for children's development.

\section{Keywords}

Family; family climate; emotional and behavioral problems; children. 


\section{Resumen}

Leusin, Joanna Ferreira; Borsa, Juliane Callegaro (Tutor). Clima familiar y los problemas emocionales y de comportamiento de una muestra de niños de Rio de Janeiro. Rio de Janeiro, 2017, 71p. Dissertação de Mestrado - Departamento de Psicologia, Pontifícia Universidade Católica do Rio de Janeiro.

La literatura está demostrado la fuerte influencia de la familia y sus interacciones sobre el desarrollo de los/as niños/as. Este estudio se enfoca en comprender la importancia de la familia para el desarrollo infantil, específicamente la influencia del clima familiar y de las características familiares en el surgimiento de problemas emocionales y conductuales en los/as niños/as. Para comprender la relación entre el clima familiar y los problemas emocionales y conductuales de los/as niños/as, se utilizó como base teórica el Enfoque Bioecológico del Desarrollo Humano e investigaciones similares que trabajaron el tema. Con esa intención, se investigó, en una muestra de niños/as de la ciudad de Río de Janeiro, la relación entre el clima familiar, las características sociodemográficas de la familia y los problemas emocionales y conductuales en la infancia. Participaron 237 familias, entre los encuestados, 168 madres, 39 padres y 30 cuidadores de niños/as, entre 7 y 13 años, matriculados en escuelas de enseñanza primaria de Río de Janeiro. Los datos fueron recogidos por medio del Inventario de Clima Familiar, el Child Behavior Checklist y de un cuestionario sociodemográfico. O clima familiar presento asociación con las variables renta familiar, salud mental y escolaridad de los padres. Correlaciones de Pearson y regresiones lineares multiplas indicaran asociación negativa entre apoyo y el cohesión familiar y los problemas emocionales/comportamentales de los niños. También, conflicto y jerarquía de la familia presentaran relación positiva con estos problemas. Los resultados indican que los procesos proximales, específicamente el clima familiar, son una importante fuente de protección para el desarrollo de los niños.

\section{Palabras clave}

Família; clima familiar; problemas emocionales o comportamentales; niños. 


\section{Sumário}

1. Introdução 10

2. Revisão teórica 13

2.1 A família no desenvolvimento infantil 14

$\begin{array}{ll}2.2 \text { Clima familiar } & 17\end{array}$

2.3 Problemas emocionais e comportamentais das crianças 22

2.4 Características familiares e problemas comportamentais e emocionais das crianças 24

3. Estudo empírico 31

3.1 Método 33

$\begin{array}{ll}3.2 \text { Resultados } & 37\end{array}$

3.3 Discussão $\quad 41$

4. Considerações finais 46

5. Referências bibliográficas $\quad 49$

6. Anexos $\quad 57$

6.1 Anexo I - Parecer do Comitê de Ética 57

6.2 Anexo II - Carta de apresentação à escola e aos pais 60

6.3 Anexo III - Modelo carta de autorização para a escola 61

6.4 Anexo IV - Questionário biossociodemográfico 62

6.5 Anexo V - Child Behavior Checklist - CBLC 6/18 66

6.6 Anexo VI - Inventário do Clima Familiar (ICF) 70 


\section{Lista de Tabelas}

Tabela 1 - Correlações do ICF e variáveis sociodemográficas

Tabela 2 - Correlação entre o Inventário de Clima Familiar e o Child Behavior Checklist

Tabela 3 - Análises de regressão linear múltipla (método enter) do ICF nos fatores do CBCL 


\section{Introdução}

O ambiente familiar é considerado na literatura o primeiro e mais importante contexto interpessoal para o desenvolvimento humano (MINUCHIN, 1995. TEODORO; CARDOSO; FREITAS, 2010). Por meio das relações familiares, a criança desenvolve suas crenças, seus valores, seus padrões de comportamento, sua comunicação, entre outros fatores que contribuem para o seu desenvolvimento (KREPPENER, 2000. SEILD-DE-MOURA; PESSSÔA, 2009). Segundo a perspectiva sistêmica, a família é mais do que um conjunto de indivíduos. É um sistema que está em constante movimento, no qual o comportamento de um membro influenciará os demais (BERTALANFFY, 1973. MINUCHIN, 1982. BRONFENBRENNER, 1996. NICHOLS; SCHWARTZ, 2007).

Este estudo utiliza como aparato teórico a Abordagem Bioecológica do desenvolvimento humano de Bronfrenbrenner (1979/1996), que tem como destaque a compreensão do indivíduo através da sua relação com os contextos em que ele está inserido. Especificamente neste estudo, será investigado o contexto familiar da criança, em especial o clima familiar. A Abordagem Bioecológica propõe que as características da criança, família e ambiente podem se configurar como fatores de proteção ou de risco para o desenvolvimento infantil, auxiliando ou não a criança na aquisição de habilidades emocionais e comportamentais (BRONFRENBRENNER; MORRIS, 1998).

As características familiares vêm sendo associadas a uma série de comportamentos através dos quais o indivíduo inicia e mantém relações afetivas. Portanto, o desenvolvimento da afetividade - ou seja, os vínculos emocionais - tem seu início no contexto familiar (ROHENKOHL; CASTRO, 2012). Além do afeto, que seria a coesão na família, o apoio familiar é apontado como fator positivo para o desenvolvimento infantil; enquanto o conflito e a hierarquia são considerados variáveis negativas para o funcionamento familiar (DE ANTONIO; TEODORO; KOLLER, 2009).

Outras características familiares, como as sociodemográficas, também são associadas aos problemas de comportamento das crianças, podendo estes serem externalizantes ou internalizantes (BARNETT; HUNTER, 2012). Desta forma, a 
estrutura e as características familiares podem afetar diretamente a formação dos repertórios comportamentais das crianças (DESSEN; POLONIA, 2007).

$\mathrm{Na}$ infância, as experiências geram impacto significativo no desenvolvimento da personalidade e, consequentemente, nas interações sociais do indivíduo (BRONFENBRENNER, 1996). Portanto, nota-se que para compreender a existência dos problemas emocionais e comportamentais das crianças deve-se considerar os ambientes com os quais ela interage, principalmente o familiar, uma vez que o mesmo tem forte influência nos comportamentos infantis (MINUCHIN, 1990).

Considerando a importância das interações familiares, o presente estudo se propõe a averiguar a relação existente entre o clima familiar e os problemas emocionais e comportamentais das crianças. Destaca-se que a presente pesquisa é um recorte de uma pesquisa mais ampla, intitulada de "Prevalência dos comportamentos agressivos em escolas da cidade do Rio de Janeiro".

Entre os instrumentos dessa pesquisa maior, foi utilizado o questionário sociodemográfico, escolhido para listar características das famílias e o inventário de clima familiar para levantar a presença de conflito, hierarquia, apoio e coesão familiar, que serão explanados ao longo do trabalho. Por fim, o instrumento Child Behavior Checklist - CBCL 6/18 que fornece, a partir das respostas do responsável pela criança, a presença ou não de problemas emocionais e comportamentais infantis, diferenciando entre problemas externalizantes e internalizantes. A seleção destes instrumentos foi originada a partir do objetivo do estudo em relacionar o clima familiar com os problemas emocionais e comportamentais infantis.

Inicialmente, é apresentada uma revisão da literatura sobre o desenvolvimento infantil, a importância do ambiente familiar nesse desenvolvimento, a influência do clima familiar, além das características familiares na presença de problemas emocionais e comportamentais das crianças. Nesta etapa, buscou-se conhecer pesquisas com objetivos semelhantes, com vistas a averiguar a prevalência dos problemas infantis e suas relações com o ambiente familiar. Tal revisão serve como base qualificada de informação para propiciar um melhor entendimento dos resultados que foram obtidos.

A etapa seguinte trata do estudo empírico sobre o tema em questão, em uma amostra de crianças da cidade do Rio de Janeiro. Por fim, nas considerações finais, é comentada a contribuição do mesmo tanto para o meio científico, quanto para a 
sociedade como um todo, destacando a importância de se considerar as variáveis familiares para compreensão do desenvolvimento infantil. 


\section{Revisão teórica}

$\mathrm{Na}$ infância, as relações familiares são fundamentais para a inserção da criança no convívio social, pois é onde, inicialmente, a criança aprende a criar laços afetivos e se reconhecer como indivíduo (DESSEN; POLONIA, 2007). Por essa razão, o sistema familiar vem ganhando cada vez mais espaço nas pesquisas científicas, visto que é no seio da família que a criança desenvolve suas habilidades emocionais e comportamentais (LA TAILLE, 2003).

$\mathrm{Na}$ família, a criança estabelece suas primeiras relações interpessoais. Dentro deste núcleo, ela aprende a viver em sociedade, desenvolvendo, assim, sua identidade (SZYMANSKI, 2004). Tal processo ocorre através da interação efetiva entre os membros da família e oportuniza uma rede de apoio familiar, que fortalecerá a criança para enfrentar futuros problemas de diversos âmbitos, tais como os sociais, os escolares e os financeiros (SZYMANSKI, 2004. TEODORO; CARDOSO; FREITAS, 2010). Na infância é quando também surgem, de forma significativa, possíveis problemas emocionais e comportamentais, podendo gerar prejuízos expressivos para o desenvolvimento infantil (BORSA E BANDEIRA, 2014).

A configuração de recursos que são relevantes para o desempenho muda à medida que a criança se desenvolve. Entretanto, os efeitos do ambiente familiar têm sido identificados nos diferentes níveis de ensino: na educação infantil, no ensino fundamental, no ensino médio e até mesmo na universidade (MATURANO, 2006). Portanto, variáveis familiares contribuem para o aparecimento de problemas na fase escolar, assim como a presença de recursos para a criança lidar com as possíveis dificuldades da infância (FERREIRA E MATURANO, 2002).

Para a Abordagem Bioecológica do Desenvolvimento Humano (Bronfenbrenner, 1996), os contextos de desenvolvimento humano funcionariam de forma encaixada, influenciando e sendo influenciados uns pelos outros. A família, um dos microssistemas de desenvolvimento infantil, faz parte deste mecanismo, provocando e sofrendo influências de outros contextos, como o bairro, o trabalho e a escola. Estes diferentes contextos interagem ao longo do ciclo vital e são acompanhados pelas transformações biológicas do indivíduo. 
Numa ótica sistêmica, podemos entender a família como uma estrutura complexa de indivíduos que são interdependentes, onde as experiências tidas por um membro têm impacto tanto em um outro membro, como no sistema em que este se encontra inserido (Alarcão, 2000). Dias (2011) destaca a existência de múltiplas estruturas familiares na contemporaneidade. Desta forma, se torna importante conhecer as características da família para entender o desenvolvimento da criança.

\section{1}

\section{A família no desenvolvimento infantil, segundo a abordagem Bioecológica do Desenvolvimento Humano de Urie Bronfrenbrenner}

A família é vista como o meio primordial do desenvolvimento infantil. Diversos estudos realizados ao longo dos últimos anos buscam entender a relação entre o contexto familiar e o comportamento da criança (FERREIRA; MATURANO, 2002. COUTINHO, 2004. MARTINS; SZYMANSKI, 2004. FONSECA, 2005. DESSEN; SZELBRACIKOWSKI, 2006. BOING; CREPALDI; MORÉ, 2008. LEVY; JOANATHAN, 2010). Na primeira infância, os principais vínculos, bem como os cuidados e estímulos necessários ao crescimento e desenvolvimento, são fornecidos pela família. A qualidade do cuidado, nos aspectos físico e afetivo-social, decorre de condições estáveis de vida, tanto socioeconômicas quanto psicossociais (ANDRADE et. Al., 2005)

A presença de uma criança na família gera uma mudança na organização da mesma, exigindo que os seus membros se reorganizem, tanto em suas funções, quanto em seus papéis (MINUCHIN, 1980; CARTER; MCGOLDRICK, 1995). A família desempenha, ainda, o papel de mediadora entre a criança e a sociedade, possibilitando a sua socialização, elemento essencial para o desenvolvimento infantil. A mesma é um sistema aberto, que se desenvolve na troca de relações com outros sistemas. Desta forma, olhar para criança é olhar para o contexto familiar em que ela está inserida (ANDRADE et. Al., 2005).

Portanto, para entender a criança e suas relações no sistema familiar, buscou-se, no presente estudo, utilizar a perspectiva bioecológica desenvolvida por Urie Bronfenbrenner (1979/1989), a qual sugere que a criança cresce em um ambiente social complexo, com diversos integrantes (irmãos, pais, mães, avós, 
professores, etc.), que estão inseridos dentro de um sistema social maior, como a cultura, os valores, o ambiente de trabalho, a comunidade que residem, entre outros. Todos esses fatores devem ser considerados para a correta compreensão do desenvolvimento da criança. A relação dos pais com um ambiente social mais amplo tem efeito direto no modo como esses agem com seus filhos e viabilizam o desenvolvimento dos mesmos (SILVA, NUNES, et. al., 2008).

Bronfenbrenner (1996) aponta para a complexidade dos múltiplos contextos em que o indivíduo se desenvolve, ocorrendo uma interdependência constante entre os sistemas presentes. Segundo o autor, são quatro os níveis ambientais que influenciam o desenvolvimento infantil: microssistema, mesossistema, exossistema e macrossistema. O sujeito, com suas características individuais (sexo, idade, temperamento, etc.), tem a família como o seu microssistema primário e mais próximo, aparecendo depois os demais microssistemas, tais como escola, vizinhança, entre outros.

É no microssistema que ocorrem os principais suportes do desenvolvimento infantil. Tais suportes podem determinar as trajetórias de vida do indivíduo, de maneira a favorecer ou inibir suas expressões emocionais, cognitivas e sociais (BRONFENBRENNER, 1996). Bronfenbrenner e Morris (1998) afirmam que no microssistema acontecem os processos proximais de interação entre o indivíduo e seus ambientes. Estes processos operam no tempo e se constituem nos mecanismos primários do desenvolvimento humano, sendo os principais motores do desenvolvimento da criança.

Os processos proximais são relações de reciprocidade entre as pessoas da família e suas crianças, pois, como apontam Bronfrenbrenner e Morris (1998), o desenvolvimento humano ocorre permeado por esses processos progressivos de interação. Desta forma, quando os pais cuidam ou alimentam um bebê, adultos da família brincam com uma criança, irmãos ou primos da mesma idade interagem, ouvem uma história ou adquirem novos conhecimentos, praticam atividades esportivas ou resolvem algum problema, estão desempenhando atividades permeadas por processos proximais (BRONFENBRENNER; MORRIS 1998).

A família é a primeira rede de apoio da criança, iniciada muito cedo com as primeiras relações de apego. Ela pode apresentar fatores de proteção e risco, dependendo do seu funcionamento e da sua dinâmica (MORAIS E KOLLER, 2004). As autoras ressaltam que diferentes aspectos interagem entre si em um 
processo que pode produzir uma experiência estressora ou protetora em seus efeitos. Segundo Siqueira e Dell’́Aglio, práticas educativas saudáveis, bom funcionamento familiar, vínculo afetivo, apoio e monitoramento parental operam nas famílias como fatores de proteção. Eles são entendidos como fatores ou processos que reduzem o impacto do risco e exercem efeitos positivos na saúde mental do indivíduo, podendo operar como pontos de apoio, além de contribuir para uma adaptação bem sucedida e promover a resiliência (SIQUEIRA E DELL'AGLIO, 2007; POLETO E KOLLER, 2008).

Polleto e Koller (2008), que se aprofundaram na teoria bioecológica de Bronfrenbrenner, sinalizam que a família contribui para a presença dos fatores protetivos ou de risco, como, por exemplo, ao proporcionar o alicerce necessário para a sobrevivência e socialização da criança através de um vínculo positivo, no qual o apoio e a coesão familiar estão presentes para criança se desenvolver. Por outro lado, a presença de discórdia conjugal, doença mental de um dos pais, habilidades parentais disfuncionais e dificuldades financeiras podem se tornar fatores de risco para o desenvolvimento infantil. Greenberg, Domitrovitch e Bumbarger (2001) apontam que o desenvolvimento não é determinado por um simples fator de risco, mas multideterminado por relações complexas entre as variáveis biológicas e as ambientais.

Os fatores de risco para o desenvolvimento do indivíduo estão relacionados aos eventos negativos vividos pelo mesmo, pois podem gerar problemas físicos, emocionais e comportamentais (BRONFENBRENNER; MORIS, 1998). Maia e Willians (2005) apontam experiências estressoras que podem prejudicar o desenvolvimento saudável infantil, tais como: conflitos familiares, divórcio dos pais, abuso sexual e/ou físico contra crianças, pobreza e empobrecimento, desastres e catástrofes naturais, guerras e outras formas de trauma. Porém, ressalta-se que a intensidade dessa experiência estressora é singular, podendo ocorrer de várias formas, dependendo do modo como elas são percebidas. A cumplicidade e a comunicação entre os genitores também influenciam no desenvolvimento emocional das crianças. É possível perceber, por exemplo, que os casais que se divorciam podem ter dificuldades nessa esfera, visto que conflitos conjugais são frequentes em alguns divórcios (WAGNER; PREDEBON; VERZA, 2005).

Rohenkohl e Castro (2012) postulam que estes conflitos, muitas vezes apresentados através de discussões e ofensas, criam alianças e distanciamento entre 
os membros da família. Considerando que toda relação envolve algum nível de conflito, é importante entender o quanto esse processo de divórcio pode afetar o desenvolvimento dos filhos. O estudo de Wagner, Predebon e Verza (2005), que teve como objetivo entender a importância de os pais compartilharem as tarefas educativas, sinalizou que a maioria dos genitores entrevistados estavam de acordo que a relação conjugal satisfatória tem grande importância no desempenho de suas tarefas educativas, enquanto pai/mãe e filho. Portanto, o afeto e o conflito têm efeito significativo no sistema familiar e no bem-estar da criança (TEODORO, 2006).

Em suma, Poletto e Koller (2008) salientam que os fatores de proteção são essenciais para o desenvolvimento. São eles: autoestima, autonomia, recursos financeiros, orientação social positiva, rede social, coesão familiar, ausência de negligência, possibilidade de administrar conflitos, presença de laços afetivos no sistema familiar e presença posterior de laços em outros contextos sociais. Osti (2016) corrobora ao constatar que a interação dos pais com filhos quanto à dinâmica familiar, as condições de vida e os recursos do ambiente associados à dedicação dos pais podem ser fontes saudáveis para o desenvolvimento da criança.

A manutenção da saúde familiar não depende apenas da capacidade de superar crises, mas, sobretudo, da boa qualidade das relações entre seus membros e das trocas familiares com o meio social (PRATTA E SANTOS, 2007). Assim, a falta de harmonia e baixa qualidade do relacionamento familiar e conjugal são aspectos importantes, uma vez que influenciam diretamente o desenvolvimento dos filhos e podem culminar no aparecimento de dificuldades e na maior prevalência dos transtornos psicológicos e suas comorbidades nesta fase de vida dos indivíduos (PRATTA E SANTOS, 2007; TEODORO, SARAIVA E CARDOSO, 2014).

A partir desse olhar bioecológico, que enfatiza a importância das interações familiares, dos fatores de risco e proteção, o presente estudo utilizou o conceito de Clima Familiar para averiguar, especificamente, as características presentes na interação da criança com sua família.

\section{2}

\section{Clima familiar}

Segundo Teodoro, Allgayer e Land (2009), o ambiente familiar é definido de acordo com a percepção dos seus membros sobre os relacionamentos dentro do 
sistema familiar, o crescimento pessoal, a organização e o controle do sistema. Os autores utilizam a avaliação do clima familiar para compreender as relações familiares.

O clima familiar refere-se à percepção de diversas características dos relacionamentos intrafamiliares pelos membros da família. A avaliação deste pode contribuir para os entendimentos teórico e clínico da dinâmica familiar (TEODORO; ALLGAYER; LAND, 2009). Segundo MINUCHIN (1995), ao longo do ciclo vital da família, são estabelecidos padrões de interação recorrentes e rígidos, caracterizando a estrutura familiar e, consequentemente, originando alianças, conflitos, hierarquias e regras dentro do contexto familiar.

A avaliação do clima familiar vem sendo realizada por meio de diferentes escalas, com diferentes estruturas fatoriais. Teodoro, Allgayer e Land (2009) desenvolveram um instrumento para avaliar o clima familiar por meio de quatro dimensões: o conflito, a hierarquia, o apoio e a coesão - todas investigadas ao longo do presente estudo. Pesquisas revelam a associação do clima familiar e características familiares com problemas comportamentais das crianças (PETRUCCI; BORSA; KOLLER, 2016).

Segundo Bronfenbrenner e Morris (1998), as características individuais da pessoa estão ligadas às interações que ela vive no meio em que está inserida, principalmente na fase da infância, quando os seus cuidadores são seu "espelho", fazendo com que ela consiga se enxergar e se analisar como pessoa. Desta forma, ambientes que favorecem sentimentos positivos contribuem para que as crianças tenham uma visão positiva de si mesmas. Petrucci, Borsa e Koller (2016) reforçam esse pensamento ao concluir que crianças que se desenvolvem em ambientes familiares que oferecem suporte e apoio emocional geralmente se adaptam a novos contextos com mais facilidade, comparadas a crianças que se desenvolvem em ambientes familiares conflituosos e hostis, as quais tendem a apresentar dificuldades na adaptação a novos ambientes e nas exigências da vida em sociedade.

O construto conflito está relacionado à relação agressiva, crítica e conflituosa entre os membros da família (TEODORO; ALLGAYER; LAND, 2009). Segundo Minuchin (1990), dentro do contexto familiar existem subsistemas (parental, conjugal e fraternal) que podem ser flexíveis ou rígidos. Famílias com subsistemas rígidos sinalizam a dificuldade de encontrar apoio no subsistema, o que pode causar um conflito entre as partes. O conflito é caracterizado por sentimentos 
negativos que podem gerar estresse e agressividade no ambiente familiar, além de ser um risco para saúde mental e física dos membros da família (TEODORO; ALLGAYER; LAND, 2009. ROHENKOHL; CASTRO, 2012).

A ocorrência de conflitos dentro do seio da família pode acarretar violência entre membros, gerando sofrimento e problemas fora do ambiente familiar (REICHENHEIM, HASSELMANN; MORAES, 1999). A violência na família é um fator de risco para o desenvolvimento infantil, além disso, pais agressivos possuem características comportamentais problemáticas, ocasionando menos interação com seus filhos e menor compressão do papel parental (SÁ; BORDIN, et. al., 2010).

Já o construto hierarquia investiga uma diferenciação clara de poder dentro da família, na qual as pessoas mais velhas possuem influência nas decisões. Esta dimensão representa o nível de controle e de poder dentro da família (TEODORO; ALLGAYER; LAND, 2009). Os padrões que organizam a estrutura familiar estão presentes em todas as famílias e são fundamentais para a interação saudável entre os seus membros. Existem hierarquias que podem ser extremamente fracas, nas quais os mais jovens exercem um poder sobre os mais velhos, ou hierarquias extremamente rígidas, que dificultam a autonomia dos membros e podem gerar conflitos pela disputa de poder (NICHOLS; SCHWARTZ, 1998). Um ambiente familiar saudável geralmente possuí um padrão de autoridade flexível e claro entre os membros (MINUCHIN, 1990).

Segundo Del Prette e Del Prette (2005), a comunicação entre pais e filhos é um aspecto favorecedor para formação de um autoconceito satisfatório dos filhos. Famílias nas quais existem espaços para comunicação entre os seus membros, em que os pais conseguem ter uma relação harmoniosa e nas quais as regras e decisões são compartilhadas, possibilitando que as crianças se expressem e exprimam suas opiniões, proporcionam um ambiente de apoio para os membros (SOUZA; BAPTISTA; ALVES, 2008).

O inventário do clima familiar também avalia o construto apoio, o qual descreve o suporte emocional e material entre os membros da família (TEODORO; ALLGAYER; LAND, 2009). O apoio ou suporte familiar é fundamental para o desenvolvimento da criança e acontece por meio do carinho, da comunicação, da presença e da participação dos pais na vida de seus filhos (NICHOLS; SCHWARTZ, 2007). O suporte dos pais em relação ao desenvolvimento dos filhos 
auxilia as crianças a se sentirem mais capazes em lidar com as demandas da sociedade, capacitando-as a se ajustar aos ambientes que interage, além de auxiliar em seu desempenho intelectual e em sua visão de si mesmas (ROHENKOHL; CASTRO,2012). O sentimento de pertença é primeiramente desenvolvido na família através do diálogo, da relação conjugal integrada e a liderança compartilhada com os filhos de forma democrática, e não coerciva (SOUZA; BAPTISTA; ALVES, 2008).

O construto coesão é definido pelo vínculo emocional, ou seja, o afeto entre os membros da família (TEODORO; ALLGAYER; LAND, 2009). Segundo Minuchin, Nichols e Lee (2009), as famílias com relacionamentos coesos geralmente apresentam um funcionamento saudável. Por outro lado, as famílias menos coesas tendem a apresentar mais conflitos entre os seus membros. Os autores ressalvam a presença das alianças na família, que podem sinalizar a coesão. Bronfenbrenner (1996) afirma que a coesão dentro do contexto familiar é um fator positivo para o desenvolvimento saudável do indivíduo. De acordo com De Antoni, Teodoro e Koller (2009), a coesão familiar influencia o bem-estar psicossocial de todos os integrantes da família, além de desenvolver as habilidades emocionais e sociais das crianças. Famílias com relacionamentos coesos tendem a ser mais funcionais que aquelas com relacionamentos pouco coesos, sendo que essas últimas podem vir a apresentar conflitos familiares frequentes.

Vale destacar que estes construtos são considerados a partir dos estudos de Teodoro, Allgayer e Land (2009) para a construção do inventário de clima familiar, usado na presente pesquisa. Sua primeira elaboração ocorreu na década de 1970, por meio do instrumento Family Environment Scale (FES) (MOOS, 1974), escala que permite o conhecimento de diferentes aspectos da família, como qualidade do relacionamento emocional. Porém, as novas formas e elaboração do clima familiar acabaram se modificando em relação à original, proposta por Moos (1974). Com isso, foi elaborada uma nova versão do ICF com 32 itens, por Teodoro, Allgayer e Land (2007), sendo esta a considerada neste estudo.

Ao considerar esses construtos importantes para entender as características familiares, nota-se a importância de destacar a coesão familiar, ou seja, o afeto presente na família que pode ser avaliada pelo inventário através do construto de coesão familiar, o qual refere-se a um conjunto de emoções positivas que existem no relacionamento interpessoal, revelando carinho e cuidado pelo outro 
(TEODORO; ALLGAYER; LAND, 2009). Os laços afetivos, ou seja, os vínculos emocionais, proporcionam apoio psicológico e social na família, auxiliando a criança no enfretamento das dificuldades da vida em sociedade (ROHENKOHL; CASTRO, 2012).

Dessen e Polonia (2007) afirmam que a relação pais-filhos é preditora do desenvolvimento saudável e, consequentemente, de interações fora do ambiente familiar positivas e afetuosas. Em contrapartida, famílias com conflitos e pais autoritários frequentemente apresentam baixa coesão e baixo apoio entre os membros (DE ANTONI; TEODORO; KOLLER, 2008). Essa constatação vem ao encontro das pesquisas realizadas para desenvolver o inventário de clima familiar, por Teodoro, Allgayer e Land (2009). Estes apontam para a existência de dois polos no clima familiar: o polo positivo (coesão e apoio) e polo negativo (conflito e hierarquia).

A percepção do clima familiar é influenciada pelas características individuais de cada membro da família (SBICIGO; DELL'AGLIO, 2012) e a qualidade dos relacionamentos intrafamiliares (TEODORO; ALLGAYER; LAND, 2009). Nesse sentido, pessoas de uma mesma família podem apresentar diferentes percepções do clima familiar, revelando uma adaptação singular frente às demandas da vida (SBICIGO; DELL'AGLIO, 2012).

Segundo Petrucci, Borsa e Koller (2016), crianças com ambientes familiares que oferecem suporte emocional e social tendem a se adaptar com mais facilidade a novos contextos, enquanto crianças que vivenciam ambientes familiares conflituosos podem ter dificuldades de adaptação em outros contextos. Estudos apontam que as relações afetivas estabelecidas na família constituem um dos fatores determinantes para o desenvolvimento emocional das crianças. A pesquisa de Rohenkohl e Castro (2012), por exemplo, revelou resultados significativos ao relacionar afetividade e conflito dos pais e comportamento das crianças.

Diversos estudos apontam para o impacto negativo dos conflitos conjugais no desenvolvimento psicológico dos filhos, especialmente nas situações familiares envolvendo violência física e verbal entre o casal (BENETTI, 2006). A autora afirma que os conflitos conjugais podem estar relacionados a distúrbios em diferentes aspectos do desenvolvimento de crianças e adolescentes, como nas áreas emocional, cognitiva e social. 
Diante desta constatação, é possível afirmar que o microssistema familiar e suas interações, influenciados pelo comportamento e pelas características emocionais e afetivas dos membros da família, estão diretamente ligados aos problemas comportamentais e emocionais da criança na fase escolar (BORSA; PETRUCCI; KOLLER, 2015). Nota-se a pertinência em compreender a relação do clima familiar e das características familiares e com problemas emocionais/comportamentais de crianças.

Os construtos avaliados pelo inventário de clima familiar podem configurar como fatores de risco ou de proteção relacionados ao desenvolvimento das crianças (TEODORO; CARDOSO; PEREIRA, 2011). Os resultados negativos gerados pela baixa qualidade das interações e do clima familiar podem estar presentes desde a infância, gerando problemas comportamentais e emocionais para as crianças (TEODORO, CARDOSO E SARAIVA, 2014).

\section{3}

\section{Problemas Emocionais e Comportamentais na Infância}

Os problemas comportamentais e emocionais infantis, considerados no presente estudo, podem ser classificados como internalizantes ou externalizantes. Os internalizantes são aqueles caracterizados por retraimento e ansiedade, preocupação exagerada, tristeza, insegurança, timidez, medos, manifestações psicossomáticas, recusa escolar, dentre outros. Já os externalizantes caracterizamse por agressividade, impulsividade, agitação, atitudes desafiantes, manipulação, desrespeito a limites e regras, brigas, hostilidade nas relações, entre outros (ACHENBACH, 2001).

Segundo Borsa e Nunes (2008), os comportamentos de internalização são os de padrões privados desajustados, como a tristeza e o isolamento, sendo mais restritos ao mundo interno da criança. Talvez por isso sejam mais difíceis de serem identificados, tanto pelos pais quanto, e principalmente, pelos professores. Já os comportamentos de externalização, como a agressividade, a agitação psicomotora e o comportamento delinquente, por serem aqueles visivelmente desajustados em relação ao aceito socialmente, são identificados com maior facilidade. 
Szelbracikowski e Dessen (2007) complementam os exemplos de comportamentos de externalização citando as agressões físicas e verbais, o roubo, a mentira, dentre outros comportamentos de descumprimento de regras sociais e de problemas de conduta. Ambas manifestações dos problemas de comportamento dificultam o desenvolvimento psicossocial da criança, já que podem privá-la de interagir com o ambiente. Com isso, o indivíduo pode evitar o início de uma interação quando sofre de problemas comportamentais de internalização ou quando apresenta problemas de comportamento de externalização, podendo gerar conflitos e provocar rejeição de pais, professores e colegas (GONÇALVES; MURTA, 2008).

Segundo Wolff e Ollendick (2006), atualmente existe um reconhecimento maior de que as crianças podem apresentar comorbidades com os seus problemas comportamentais e emocionais, gerando implicações significativas para o tratamento e prognósticos das mesmas. Pedrini e Frizzo (2010) corroboram ao averiguar que a presença de comorbidades vem crescendo e tornando ainda mais complexo o tratamento de crianças com problemas emocionais e comportamentais.

As autoras Ferreira e Maturano (2002) apontam a associação entre as dificuldades escolares com problemas emocionais e comportamentais das crianças (FERREIRA E MATURANO, 2002). Portanto, desempenhos escolares adequados estão associados a uma melhor adaptação social (TEIXEIRA; SERACENI et. al., 2014).

Os autores Teodoro, Saraiva e Cardoso (2014) reforçam essa ideia ao apontarem que crianças com desempenho escolar pobre frequentemente apresentam problemas externalizantes. Os autores salientam que nos primeiros anos de vida escolar os problemas internalizantes também se manifestam, porém prevalecem os sinais de hiperatividade e impulsividade. Lins et. al. (2012) explicam que os problemas externalizantes são manifestações comportamentais que se voltam contra o ambiente. Portanto, podem ser mais facilmente identificadas por observadores externos, como pais, professores ou cuidadores.

Para Bolsoni-Silva, Loureiro e Maturano (2016), os problemas internalizantes tendem a não ser identificados e carecem de estudos investigativos sobre estes sintomas. As autoras destacam a importância de considerarmos esses sintomas, já que podem trazer efeitos nocivos para o desenvolvimento das crianças, como o surgimento de transtornos mentais. 
Segundo Ferreira e Barreira (2010), existem múltiplas variáveis que podem ser associadas aos problemas comportamentais e emocionais. Todavia, o ambiente familiar se destaca como uma variável relevante para ocorrência destes problemas. Os autores sinalizam que é no contexto familiar que a criança encontra recursos para potencializar suas habilidades cognitivas e sociais, como jogos, livros e suporte emocional para facilitar a aprendizagem e adaptação em outros ambientes. Famílias com interações satisfatórias e adequadas podem ser consideradas como fatores de proteção para saúde mental das crianças (SÁ, BORDIN et. al., 2010. PORTUGAL; ALBERTO, 2013).

\section{4}

Características Familiares e Problemas Emocionais e Comportamentais das crianças

Por meio do suporte familiar, a criança constrói a sua identidade. Os vínculos criados no contexto familiar serão a base para autoestima da criança e para a sua competência de construir relações interpessoais fora do ambiente familiar (LEVY \& JONATHAN, 2010). Nota-se, assim, que a análise da família como contexto de desenvolvimento infantil constitui-se um fenômeno complexo, no qual devem ser considerados diferentes fatores, tais como a renda familiar, a presença de doença mental ou física, o apoio familiar, o conflito familiar, a escolaridade dos pais, os eventos estressores, entre outros (SILVA; NUNES, et. al., 2008. LEME; MARTURANO; FONTAINE, 2014. TEIXEIRA et. al., 2014. PETRUCCI; BORSA; KOLLER, 2016).

Em pesquisas atuais, as características familiares são associadas aos problemas de comportamentos externalizantes e internalizantes em crianças e à qualidade de vida dos membros da família em geral (OSÓRIO, 2002; BARNETT; HUNTER, 2012). Porém, o presente estudo selecionou pesquisas que auxiliassem a compreender algumas características familiares que se relacionavam com os problemas emocionais e comportamentais das crianças, dando atenção para as características da interação da família, como a presença de conflito, hierarquia, apoio e coesão familiar. 
Crianças que não apresentam problemas comportamentais são as que têm maior presença dos pais em relação a compartilharem sentimentos e problemas com os mesmos (FERREIRA; MATURANO, 2002). Os estudos de Weber, Prado et. al. (2004) e Del Prette e Del Prette (2005) concluíram que os comportamentos das crianças estão diretamente ligados aos estilos parentais, ou seja, à conduta que os pais assumem frente à criação de seus filhos. Outro fator que está associado à presença de problemas comportamentais e emocionais das crianças são as dificuldades escolares (FERREIRA E MATURANO, 2002). Portanto, desempenhos escolares adequados estão associados a uma melhor adaptação escolar (TEIXEIRA; SERACENI et. al., 2014). Segundo D'Avila- Bacarji, Marturano e Elis (2005), a dificuldade de aprendizagem é o principal motivo de encaminhamento para atendimento psicológico na rede pública e na clínica-escola. Crianças com desempenho escolar pobre, frequentemente apresentam problemas de comportamento externalizantes (FERREIRA; MATURANO, 2002).

Merg (2008) concluiu que a maioria dos encaminhamentos de crianças para atendimento psicológico pela escola são devido às queixas de comportamento de externalização e problemas de aprendizagem. Muitas destas crianças apresentam dificuldades nos relacionamentos interpessoais e vivem em famílias que não conseguem manter o suporte emocional de que elas necessitam. $\mathrm{O}$ engajamento familiar em atividades de suporte ao desenvolvimento da criança pode ser associado à situação econômica da família. Em famílias de baixa renda, esse engajamento é um diferencial importante para o desempenho das crianças (D'AVILA-BACARJI; MATURANO; ELIS, 2005).

Nos estudos de Maia e Williams (2005) sobre características sociodemográficas e o desenvolvimento infantil, é destacada a possível influência do nível socioeconômico da família como sendo um fator de risco para o desenvolvimento da criança. Segundo diversos estudos - como os de Dessen e Szelbracikowski (2006), de Lins, Alvarenga et al. (2012) e de Petrucci, Borsa e Koller (2016) -, o nível socioeconômico e a escolaridade dos genitores podem exercer influência direta nos problemas de comportamento da criança.

Por meio do olhar da teoria bioecológica, Poletto e Koller (2008) apontam que as questões socioeconômicas podem ser prejudiciais para o desenvolvimento do ser humano. Contudo, as autoras afirmam que o determinante, nos casos de crianças criadas em ambientes de vulnerabilidade, é a forma que essas percebem 
seus eventos estressores. Por exemplo, a maneira com que uma criança lida com a violência contra ela depende de diversos fatores, tais como suas experiências anteriores, sua rede de apoio, seu momento no desenvolvimento, seus processos psicológicos e suas características individuais.

Apesar das crianças que vivem num contexto familiar de baixa renda estarem vulneráveis, Rohenkol e Castro (2012) afirmam que as práticas educativas parentais empregadas farão a diferença no desenvolvimento das crianças, ou seja, pais com baixa renda podem educar seus filhos de forma saudável. Por outro lado, Dessen e Polonia (2007) apontam que problemas comportamentais de crianças podem ser resultantes de um ambiente familiar com exposição às situações de risco.

O nível socioeconômico da família e a escolaridade dos pais são considerados por diversos autores como fatores de risco para o desenvolvimento da criança (DESSEN; SZELBRACIKOWSI, 2006. TEODORO, ALLGAYER; LAND, 2009. SAUR; CORREIA et. al., 2014. PETRUCCI; BORSA; KOLLER, 2016). Polleto e Koller (2008) salientam que as dificuldades financeiras, em muitos casos, estão alinhadas a conflitos familiares. Porém, ressalvam que famílias com coesão e suporte emocional podem transformar essas variáveis de modo a não prejudicarem o desenvolvimento infantil.

Além do nível socioeconômico e a escolaridade dos pais, também tem sido verificado que a presença de doença mental na família pode gerar prejuízos no desenvolvimento infantil (BAPTISTA; OLIVEIRA, 2004). Segundo o estudo de Cid, Matsukura e Silva (2012), mães com diagnóstico de doença mental são fatores de risco para o desenvolvimento da criança, já que em muitos casos a mãe acaba se ausentando, gerando conflitos no contexto da família e dificuldades na interação entre seus membros.

O estudo desenvolvido por Bandeira, Borsa, et. al. (2010) sobre a avaliação de problemas do comportamento infantil através do instrumento CBCL (Child Behavior Checklist) mostra que os problemas comportamentais e emocionais das crianças têm relação ao perfil de seus pais, como, por exemplo, mães depressivas (mesmo em níveis não clínicos) que podem gerar problemas de internalização em seus filhos. Já os problemas de atenção e de agressividade das crianças estão fortemente relacionados às dificuldades sociais dos pais. Pires, Silva e Assis (2012) analisaram fatores associados ao déficit de atenção e hiperatividade em crianças e constataram que a prevalência desses transtornos era maior quando havia disfunção 
familiar do que em famílias que mostravam um melhor relacionamento entre os seus integrantes.

Uma pesquisa sobre a prevalência dos problemas de comportamento em uma amostra de crianças no estado do Rio Grande do Sul, desenvolvida por Borsa, Souza e Bandeira (2011), constatou a alta incidência de comportamentos agressivos, sendo esse o principal problema do comportamento infantil. Minuchin, Nichols e Lee (2009), ao refletirem sobre os comportamentos agressivos das crianças, sugerem que os mesmos são reflexos do sistema familiar em que essas crianças se encontram inseridas. Portanto, se a criança está submetida a um sistema familiar agressivo, poderá vir a agir de forma igualmente agressiva.

Meneguel, Giuglian e Falceto (1998) ratificam essa ideia ao destacarem que crianças agressivas podem adotar os padrões de interação social que vivenciam em seu ambiente familiar. Um exemplo desta teoria é a criança que vivencia uma relação conjugal agressiva de seus pais, ou mesmo se um dos pais interage com ela de forma agressiva. Esta criança tende a ser igualmente agressiva com os seus pares, dificultando o seu ajustamento social.

O comportamento agressivo infantil pode aparecer por meio de agressão física, danos a objetos ou agressões verbais, como discussões, ameaças e bullying. Esses comportamentos agressivos podem ser acentuados com a rejeição dos pares e pela presença de hostilidade nos ambientes de interação das crianças (LISBOA; KOLLER, 2001). Segundo Bronfenbrenner Moris (1998), habilidades emocionais e sociais são desenvolvidas na sua interação com o ambiente e pelos processos proximais presentes, contribuindo para construção da personalidade da criança. Os fatores de risco para a criança relacionam-se com os eventos negativos de sua vida e quanto maior a frequência dos mesmos, maiores são as chances desta criança apresentar problemas físicos, sociais e emocionais.

As relações interpessoais necessitam de reciprocidade para que ocorra efetividade nos processos proximais e a promoção no desenvolvimento da criança (BRONFENBRENNER, 2001). Nos estudos de Squassoni, Matsukura e PanúncioPinto (2014), revela-se que o apoio familiar é o mais importante para o bem-estar dos filhos, e que os laços afetivos e o senso de pertencimento são fontes poderosas para a saúde mental das crianças.

Segundo o estudo desenvolvido por Sá, Bordin et. al. (2010), foi constatado que violência conjugal física sofrida pela mãe é um fator de risco para as crianças. 
Maia e Williams (2005) encontraram diversos estudos indicando que os efeitos nocivos resultam do fato das crianças presenciarem violência dentro de casa, sendo o conflito familiar recorrente e a falta de suporte familiar como preditores de problemas na fase da infância.

Além disso, mães que sofrem violência podem desenvolver depressão, ideação suicida, entre outros fatores prejudiciais para os processos proximais acontecerem de forma positiva para as crianças. A presença de sentimentos negativos por parte das mães tem sido associada a comportamentos problemáticos, como os sintomas depressivos e as dificuldades com a regulação emocional das crianças (YAP; SCHWARTZ et. al., 2010).

Pais punitivos e que educam por meio da agressividade tornam-se modelos para seus filhos, os quais, em muitos casos, podem apresentar nos ambientes externos da família, como a escola, comportamentos inadequados (BOLSONISILVA; MATURANO, 2002). Punição e agressão entre os membros da família geram conflitos familiares que contribuem para os problemas comportamentais das crianças (FERREIRA; MATURANO, 2002. SILVEIRA; WAGNER, 2011). Além disso, podem causar atraso no desenvolvimento cognitivo, déficit intelectual e fracasso escolar (TAVARES, LÔBO et. al., 2010).

Outra variável significativa na presença de problemas emocionais e comportamentais é a configuração de famílias recasadas. Na pesquisa de Leme, Maturano e Fontaine (2014) foi verificado que crianças de famílias nucleares apresentam mais habilidade social e menos problemas de comportamento que as crianças de famílias recasadas. A habilidade social das crianças é um fator de proteção na infância e é desenvolvida através da possibilidade de expressão de sentimentos (DEL PRETTE; DEL PRETTE, 2005). Porém, em muitos casos de divórcio as crianças não têm espaço para expressar seus sentimentos (GRZYBWSKI; WAGNER, 2010). O divórcio conflituoso poderá acarretar prejuízos no funcionamento familiar, caso não ocorra uma boa comunicação entre os seus membros (NEVES; JESUS, 2005. GRZYBWSKI; WAGNER, 2010. TAVARES, LÔBO et. al., 2010).

Pais presentes e não negligentes geram suporte emocional para os filhos, o que caracteriza um fator de proteção para o desenvolvimento destes (POLLETO E KOLLER, 2008). Ambientes familiares em que existem confiança/partilha de situações problemáticas por parte dos filhos e uma boa comunicação pais-filhos, 
configuram fatores de proteção para o desenvolvimento da criança (GRZYBOWSKI; WAGNER, 2010. PORTUGAL; ALBERTO, 2013). De acordo com o modelo bioecológico de Bronfenbrenner (2001), os processos proximais atuam como promotores do desenvolvimento. Portanto, estimular e escutar a criança possibilita a ela melhores condições para sua adaptação em novos contextos.

A ocorrência de eventos estressores na família pode gerar impacto no desenvolvimento escolar, acarretando dificuldades de concentração, problemas de memória e, principalmente, comportamento hiperativo (MATOS; CRUZ et. al., 2014). As autoras Levy e Jonathan (2010) ressaltam que, apesar dos pais se sentirem culpados com eventos como a separação, que podem influenciar a vida dos filhos de forma negativa ou não, será a conduta dos genitores que fará a diferença, pois as crianças costumam ser generosas para com seus pais. Desta forma, famílias que conseguem manter a coesão entre seus membros, apesar das dificuldades vividas em um divórcio, contribuem para o desenvolvimento saudável dos indivíduos presentes nesse microssistema (MINUCHIN, 1990. BRONFENBRENNER, 1996. TEODORO et. al., 2009).

Segundo Teixeira et. al. (2014), crianças com dificuldades escolares tendem a apresentar maiores problemas comportamentais e emocionais devido às dificuldades de adaptação social. Considerando que é no contexto familiar que a criança aprende a interagir socialmente, observa-se que a interação intrafamiliar conflituosa pode vir a ocasionar problemas sociais para a criança também em outros contextos (WHITTAKER, et. al., 2011. PETRUCCI; BORSA; KOLLER, 2016). Portanto, crianças que se desenvolvem em contextos familiares que oferecem suporte às suas necessidades demonstram alta competência social e baixos níveis de problemas de comportamento (PETRUCCI; BORSA; KOLLER, 2016).

Baptista e Oliveira (2004), em sua pesquisa, constataram que o suporte familiar inadequado, investigado na visão dos filhos, está negativamente associado à depressão. No estudo de Teodoro, Cardoso e Freitas (2010), a depressão das crianças e dos adolescentes se correlacionaram negativamente com a coesão e positivamente com conflito familiar. A presença de vínculos afetivos dentro da família se torna um fator de proteção, enquanto o conflito constitui-se num fator de risco (BRONFENBRENNER, 1996). 
O teórico Minuchin (1990) desenvolveu a ideia de fronteiras, que definem o espaço de cada membro no sistema familiar através da interação e/ou da proximidade entre os membros. Fronteiras rígidas, nas quais a hierarquia ocorre de modo opressor, geram o distanciamento emocional entre os membros e dificultando o apoio emocional dentro da família. Segundo Teodoro, Allgayer e Land (2009) famílias com relacionamentos fortemente hierárquicos apresentam pais com estilos de criação mais autoritários, fato esse que pode gerar comportamentos agressivos nas crianças. Relações mais igualitárias entre adultos e crianças possibilitam a criança uma maior capacidade de se relacionar e se comunicar fora do ambiente familiar (LEVY E JONATHAN, 2010). Por outro lado, vale salientar que os pais precisam exercer sua parentalidade como sendo agentes do desenvolvimento infantil. Segundo Tavares, Lôbo et. al. (2010), pais que não estabelecem disciplina com relação a horários e estudos, por exemplo, deixando a criança decidir se vai ou não à escola, podem causar prejuízos na aprendizagem e na interação desta com o meio.

Segundo Polleto e Koller (2008), a presença de resiliência na personalidade da criança, a partir da interação dinâmica entre as suas características individuais e os contextos que ela interage, possibilitam a esta criança o enfrentamento e a superação de crises e adversidades. Crianças que não encontram no seu ambiente familiar processos proximais efetivos, podem, através da sua relação com outros microssistemas, desenvolver-se sem gerar problemas comportamentais e emocionais, como por exemplo a escola, vizinhança e contextos que a cercam. Portanto, vale considerar que as interações familiares podem se tornar preditores de possíveis problemas emocionais e comportamentais apresentados pelas crianças. 


\section{Estudo empírico}

Diferentes perspectivas teóricas acerca do desenvolvimento humano reportam a influência do ambiente no desenvolvimento do indivíduo (BRONFENBRENNER, 1996). Especificamente, a família vem sendo amplamente estudada no campo das ciências humanas ao longo das últimas décadas (BOING; CREPALDI; MORÉ, 2008). A família é considerada o primeiro e mais importante contexto interpessoal para o desenvolvimento humano (MINUCHIN, 1995). Há diferentes fatores desse contexto que podem exercer influência nas trajetórias de desenvolvimento, dentre eles o clima familiar, que se refere às características das relações intrafamiliares, conforme avaliadas pelos seus membros (TEODORO; ALLGAYER; LAND, 2009).

O clima familiar é composto por quatro fatores: conflito, hierarquia, apoio e coesão. Conflito diz respeito à relação agressiva, crítica e conflituosa entre os membros da família. Hierarquia é definida como uma distinção rígida de poder e de controle nas relações intergeracionais dentro da família. Apoio, por sua vez, referese à existência de suporte material e emocional entre as pessoas da família. Por fim, Coesão diz respeito ao vínculo emocional entre os membros da família (TEODORO; ALLGAYER; LAND, 2010). Pesquisas acerca do clima familiar demonstram sua associação com diferentes características da infância, como problemas de comportamento (SCHULTZ; SHAW, 2003), desempenho em habilidades sociais (VALENCIA; LÓPEZ, 2011) e abuso sexual (SVEDIN; BACK; DERBACK, 2002).

Os problemas emocionais e comportamentais, particularmente, são definidos como excessos ou déficits emocionais e/ou comportamentais que causam prejuízos ao próprio indivíduo e/ou às pessoas que convivem com o mesmo (BOLSONI-SILVA; DEL PRETTE, 2003). De acordo com Achenbach (2001), eles podem ser do tipo internalizantes ou externalizantes. Os problemas internalizantes envolvem preocupação em excesso, retraimento, tristeza, insegurança e costumam ser manifestados por meio de transtornos depressivos, de ansiedade e isolamento social. Esses tipos de comportamentos não influenciam diretamente o ambiente, restringindo-se ao mundo interno da criança e, por isso, são mais dificilmente 
observados pelos cuidadores. Os problemas externalizantes, por sua vez, são manifestados no ambiente e, com isso, mais facilmente percebidos; incluem impulsividade, agressividade, hostilidade, hiperatividade, oposição, desobediência aos limites impostos e comportamentos delinquentes (ACHENBACH, 2001).

Estudos apontam para a alta prevalência de problemas emocionais e comportamentais na infância (FLEITLICH-BILYK et. al., 2010. BORSA; SOUZA; BANDEIRA, 2011) e alertam para o impacto negativo que estes comportamentos podem ter ao longo do desenvolvimento (GASPAR et. al., 2013). Além disso, a literatura tem se dedicado a compreender os fatores de risco e de proteção para o desenvolvimento de problemas emocionais e comportamentais infantis (ASSIS; AVANCI; OLIVEIRA, 2009. BORDIN et. al., 2009). Especificamente, tem-se buscado compreender a associação entre esses problemas e as características do contexto familiar (FERREIRA; MARTURANO, 2002. DESSEN; SZELBRACIKOWSKI, 2006. SBICIGO; DELL'AGLIO, 2012).

Características sociodemográficas, como baixo nível econômico, baixa escolaridade dos pais (DESSEN; SZELBRACIKOWSKI, 2006) e as práticas educativas parentais (BOLSONI-SILVA; MARTURANO, 2002), podem influenciar os problemas emocionais e comportamentais das crianças. Na revisão de literatura realizada por Petrucci, Borsa e Koller (2016), observou-se uma associação positiva entre condições socioeconômicas adversas e prejuízos no desenvolvimento infantil.

Além disso, Borsa et. al. (2011) identificaram alta prevalência de problemas de comportamento em crianças do Rio Grande do Sul e constataram uma associação entre esses problemas e as variáveis baixo nível socioeconômico, ensino em escola pública e ocorrência de separação dos pais. De acordo com as autoras, as características familiares exercem influência relevante na manifestação de problemas de comportamento na infância.

Estudos sobre o contexto familiar são complexos, visto que a família pode assumir diferentes configurações estruturais e relacionais, não pressupondo a existência de apenas um conceito de família (BOING et. al., 2008; DESSEN, 2010; DIAS, 2011; TEODORO et. al., 2009). Modelos teóricos sistêmicos, como o modelo bioecológico do desenvolvimento humano (BRONFENBRENNER, 1996), têm sido amplamente utilizados para explicar a interação da pessoa com o contexto (DINIZ; KOLLER, 2010. PETRUCCI et. al., 2016). Nela, o desenvolvimento 
humano é compreendido como o resultado da interação de diferentes fatores individuais e contextuais, sendo os processos proximais considerados como os motores do desenvolvimento. Esses processos referem-se às atividades cotidianas da pessoa em interação com outros indivíduos, objetos e símbolos do seu ambiente externo imediato, ou seja, do seu microssistema (BRONFENBRENNER, 1996).

Os processos proximais podem ser exemplificados pelas atividades que a criança realiza com os pais e irmãos, ou pelas atividades desenvolvidas com os professores e colegas. O clima familiar pode ser considerado um exemplo de processo proximal importante para o desenvolvimento, já que se refere às características de interação vivenciada pelos pais ou cuidadores e seus filhos. Dependendo da qualidade dos processos proximais, eles podem resultar em efeitos positivos ou negativos (BRONFENBRENNER, 1996). Neste sentido, problemas emocionais e comportamentais podem ser entendidos como negativos, já que prejudicam o relacionamento interpessoal, seja com os pares ou com os adultos (BOLSONI-SILVA; DEL PRETTE, 2003). Com isso, o presente estudo teve por objetivo investigar a relação entre clima familiar e problemas emocionais/comportamentais na infância. Além disso, buscou avaliar possíveis associações do clima familiar com características sociodemográficas da criança e da família.

\section{1}

\section{Método}

\subsection{1 - Participantes}

Participaram do estudo 237 cuidadores de meninos $(n=110 ; 46,4 \%)$ e meninas $(\mathrm{n}=127 ; 53,6 \%)$, com idades variando entre 7 e 13 anos $(M=9,35 ; D P=$ 1,33), matriculadas em escolas públicas $(\mathrm{n}=114 ; 48,1 \%)$ e privadas $(\mathrm{n}=123$; $51,9 \%$ ), do ensino fundamental da cidade do Rio de Janeiro. Dentre os respondentes, $168(70,6 \%)$ eram mães, $39(16,4 \%)$ eram pais e $30(13 \%)$ não informaram o grau de parentesco com a criança.

No que se refere ao nível de escolaridade dos pais, 46 (19,4\%) tinham ensino fundamental incompleto, 21 (8,9\%) tinham ensino fundamental completo, 76 $(32,1 \%)$ tinham ensino médio completo, 50 (21,1\%) tinham ensino superior 
completo, 34 (14,3\%) tinham pós-graduação completa e 10 (4,2\%) não informaram a escolaridade. Em relação à escolaridade das mães, 27 (11,4\%) tinham ensino fundamental incompleto, 29 (12,2\%) tinham ensino fundamental completo, 71 $(29,9 \%)$ tinham ensino médio completo, 62 (26,2\%) tinham ensino superior completo, $46(19,4 \%)$ tinham pós-graduação completa e duas $(0,8 \%)$ não informaram.

Por fim, em relação à renda da família, 6 (2,5\%) ganhavam até um salário mínimo, 52 (21,9\%) ganhavam entre um e três salários mínimos, 49 (20,7\%) ganhavam entre três e cinco salários mínimos, 26 (11\%) ganhavam entre seis e nove salários mínimos, 30 (12,7\%) ganhavam entre nove e doze salários mínimos e 71 (30\%) ganhavam mais de doze salários mínimos.

\subsection{2}

\section{Instrumentos}

A bateria de instrumentos utilizada para coleta de dados dos participantes do estudo foram:

i. Questionário Sociodemográfico - Foi desenvolvido para o presente estudo com o objetivo de obter informações complementares aos dados obtidos por meio dos questionários (características familiares, história de vida da criança, etc.).

ii. Inventário do Clima Familiar - ICF (TEODORO et. al., 2009) - O ICF é composto de 22 itens, que avaliam a percepção dos pais acerca das características das relações familiares a partir de quatro fatores: conflito (ex.: “Os conflitos são comuns”), hierarquia (ex.: "É comum que algumas pessoas proíbam outras de fazer determinadas coisas sem explicar o porquê"); apoio (ex.: "Procuramos ajudar as pessoas da nossa família quando percebemos que estão com problemas") e coesão (ex.: “As pessoas sentem-se felizes quando toda a família está reunida").

iii. Child Behavior Checklist - CBCL 6/18 (ACHENBACH, 2001) - O CBCL 6/18 anos é um questionário destinado aos pais/mães ou cuidadores, para que forneçam respostas referentes aos seus filhos(as) entre 6 e 18 anos de idade. Esse instrumento é composto de 138 itens, sendo 20 para avaliação da competência social da criança e 118 para avaliação dos problemas de 
comportamento. Os itens estão distribuídos em onze escalas, que correspondem a diferentes problemas emocionais/comportamentais da criança. Três dessas escalas (Atividades, Social, Escolar) compõem a Escala de Competência Social. As outras oito escalas (AnsiedadeDepressão, Isolamento-Depressão, Queixas Somáticas, Problemas Sociais, Problemas de Pensamento, Problemas de Atenção, Comportamento de Quebrar Regras/Delinquencial, Comportamento Agressivo) compõem a Escala Total de Problemas de Comportamento. Para este estudo, foram usadas apenas as oito escalas que compõem a Escala Total de Problemas de Comportamento.

\subsection{3}

\section{Procedimentos éticos}

O presente estudo é parte de um projeto mais amplo, intitulado "Prevalência dos comportamentos agressivos em escolas da cidade do Rio de Janeiro". O mesmo foi aprovado pela Comissão de Ética em Pesquisa da Universidade do Estado do Rio de Janeiro (UERJ) (CAEE: 57966816.3.0000.5282) (Anexo 1). Os participantes foram informados sobre o objetivo da pesquisa, bem como sobre os procedimentos de coleta e análise dos dados.

A privacidade dos participantes e a confidencialidade dos dados foram garantidas. Todos os dados são mantidos sob a responsabilidade da pesquisadora coordenadora deste projeto, acondicionados em caixas-arquivo mantidas à chave, com acesso restrito aos pesquisadores diretamente envolvidos no estudo. Quanto aos benefícios da pesquisa, os resultados foram devolvidos a todos os participantes que tiverem interesse em recebê-los, levando em conta os resultados gerais obtidos.

Os principais benefícios se darão indiretamente, com o avanço do conhecimento acerca da temática da relação do clima familiar com os problemas emocionais e comportamentais das crianças. Ademais, o desenvolvimento do conhecimento produzido poderá resultar em futuras estratégias de intervenção com vistas à prevenção dos problemas infantis. Não foi fornecido nenhum resultado dos participantes de forma individual. Entende-se que a participação nesta pesquisa poderá proporcionar a compreensão de pesquisadores, técnicos e da sociedade em geral sobre o desenvolvimento infantil. Visando fornecer apoio aos participantes (crianças, pais, cuidadores e professores), foi disponibilizado aos pais e à escola o 
endereço eletrônico dos pesquisadores responsáveis. Desta forma, se algum participante necessitar de acolhimento, serão sugeridas instituições de acompanhamento psicológico de caráter gratuito ou popular (com baixo custo), presentes ou próximos de seu local de residência.

\subsection{4}

\section{Procedimento de coleta de dados}

Primeiramente, foi realizado o contato pessoal ou por telefone com as escolas. Foi entregue a cada escola uma cópia resumida do projeto de pesquisa, uma carta de apresentação da pesquisa (Anexo 2) e uma carta de aceite (Anexo 3), a qual deveria ser assinada e devolvida aos pesquisadores.

Para as escolas que aceitaram participar do estudo, foram realizados alguns seguintes procedimentos. A coleta de dados, que consistiu na aplicação de um protocolo de instrumentos nas crianças e nos seus pais ou responsáveis, teve o objetivo de conhecer a prevalência de comportamentos agressivos em estudantes do Rio de Janeiro. Para o presente estudo, foram utilizados apenas os dados advindos dos questionários respondidos pelos pais, sendo eles o Questionário Sociodemográfico, ICF e CBCL, com o objetivo de averiguar as características familiares, a interação familiar e a presença ou ausência de problemas emocionais e comportamentais das crianças. Os participantes foram informados sobre o objetivo e procedimentos da pesquisa, bem como da privacidade e confidencialidade dos dados.

\subsection{5}

\section{Procedimento de análise dos dados}

Buscou-se investigar como os fatores do ICF se relacionavam com as variáveis sociodemográficas das crianças e dos pais. Correlações bivariadas de Pearson foram realizadas para avaliar possíveis associações entre os fatores do ICF e as variáveis sociodemográficas. Testes $t$ de Student foram realizados com o objetivo de avaliar se havia diferenças nos escores do ICF em relação à repetência escolar (sim/não), à separação dos pais (sim/não) e à realização de tratamento psicológico da criança ( $\operatorname{sim} /$ não). Os testes $t$ foram realizados utilizando procedimentos de bootstrapping (intervalo de confiança de 95\%), com vistas a corrigir possíveis erros de normalidade dos dados e diferenças nos tamanhos 
amostrais entre os grupos (HAUKOOS; LEWIS, 2005). O tamanho de efeito foi calculado por meio do $d$ de Cohen.

Foram realizadas correlações bivariadas de Pearson entre os fatores do ICF e do CBCL. Buscando pormenorizar tais resultados e avaliar como o clima familiar impacta nos problemas de comportamento infantil, foram realizadas análises de regressões lineares múltiplas (método enter).

\section{2}

\section{Resultados}

Inicialmente, foram realizadas correlações de Pearson entre os fatores do ICF e as seguintes variáveis sociodemográficas: nível de escolaridade do pai e da mãe, renda familiar e percepção da qualidade da saúde mental da mãe e do pai da criança. Também foram investigadas as relações do ICF com características da criança, como presença de queixa escolar, dificuldade de aprendizagem e de relacionamento (Tabela 1). Dentre os resultados, observou-se que os fatores conflito e hierarquia do ICF apresentaram correlações significativas e positivas com a saúde mental do pai. Além disso, o fator conflito correlacionou-se positivamente com a variável saúde mental da mãe. Os fatores apoio e coesão familiar apresentaram correlações positivas com as variáveis escolaridade do pai, escolaridade da mãe, renda familiar, e correlações negativas com saúde mental da mãe e saúde mental do pai.

TABELA 1:

\section{Correlações do ICF e variáveis sociodemográficas}

\begin{tabular}{lcccc}
\hline \multicolumn{1}{c}{$\begin{array}{c}\text { Variáveis } \\
\text { sociodemográficas }\end{array}$} & Conflito & Hierarquia & Apoio & Coesão \\
\hline Escolaridade (pai) & $-0,005$ & $-0,065$ & $0,171^{* *}$ & $0,196^{* *}$ \\
Escolaridade (mãe) & $-0,051$ & $-0,055$ & $0,141^{*}$ & $0,258^{* *}$ \\
Renda familiar & 0,034 & 0,004 & $0,206^{* *}$ & $0,226^{* *}$ \\
Saúde mental (mãe) & $0,360^{* *}$ & 0,104 & $-0,219^{* *}$ & $-0,325^{* *}$ \\
Saúde mental (pai) & $0,273^{* *}$ & $0,152^{*}$ & $-0,157^{*}$ & $-0,279^{* *}$ \\
\hline Nota: ${ }^{*} \mathrm{p}<0,05 ; * * \mathrm{p}<0,01$. & & & & \\
\hline
\end{tabular}


Investigou-se, também, se os escores do ICF variaram de acordo com a repetência da criança na escola, a separação dos pais e a realização de tratamento psicológico pela criança. Em relação à repetência, crianças que já haviam repetido de ano tinham maiores níveis de conflito $t(235)=2,64, p=0,05$ e menores níveis de apoio $t(235)=-2,12, p=0,05$ e de coesão familiar $t(235)=-3,70, p<0,01$. Crianças com pais separados apresentaram maiores índices de conflito $t(234)=2,03, p=0,05$ e menores índices de coesão $t(234)=-3,31, p=0,01$ quando comparadas com as que não tinham pais separados. Por fim, crianças que já haviam realizado tratamento psicológico apresentaram maiores níveis de conflito quando comparadas com as que não se submeteram a tratamento psicológico $t(234)=3,57, p=0,01$.

Quanto à correlação entre os fatores do ICF e do CBCL, os fatores conflito e hierarquia apresentaram correlação significativa e positiva com todos os indicadores de problemas de comportamento. Os fatores apoio e coesão apresentaram correlação significativa e negativa com os fatores isolamentodepressão, queixas somáticas e problemas de atenção. Além disso, o fator coesão correlacionou-se negativamente com problemas de pensamento e comportamento agressivo.

Em relação ao conflito, a maior correlação foi encontrada com comportamentos agressivos $(r=0,468 ; p<0,01)$. Em relação à hierarquia, a maior correlação se deu com problemas de atenção $(r=0,272 ; p<0,01)$. Em relação ao apoio, a maior correlação foi com o fator queixas somáticas $(r=-0,208 ; p<0,01) \mathrm{e}$ problemas de atenção $(r=-0,208 ; p<0,01)$. Por fim, em relação à coesão, a maior correlação foi com o fator queixas somáticas $(r=-0,267 ; p<0,01)$. Dentre todos os fatores do ICF, o fator conflito foi o que apresentou as correlações mais fortes com os indicadores do CBCL (Tabela 2).

\section{TABELA 2:}

Correlação entre o Inventário de Clima Familiar e o Child Behavior Checklist

\begin{tabular}{ccccc}
\hline Variáveis & Conflito & Hierarquia & Apoio & Coesão \\
\hline $\mathrm{AD}$ & $0,310^{* *}$ & $0,177^{* *}$ & $-0,005$ & $-0,093$ \\
$\mathrm{ID}$ & $0,148^{*}$ & $0,151^{*}$ & $-0,163^{*}$ & $-0,170^{* *}$ \\
\hline
\end{tabular}




\section{TABELA 2:}

Correlação entre o Inventário de Clima Familiar e o Child Behavior Checklist (continua)

\begin{tabular}{ccccc}
\hline Variáveis & Conflito & Hierarquia & Apoio & Coesão \\
\hline QS & $0,235^{* *}$ & $0,156^{*}$ & $-0,208^{* *}$ & $-0,267^{* *}$ \\
OS & $0,347^{* *}$ & $0,241^{* *}$ & $-0,072$ & $-0,106$ \\
PP & $0,309^{* *}$ & $0,156^{*}$ & $-0,116$ & $-0,143^{*}$ \\
PA & $0,442^{* *}$ & $0,272^{* *}$ & $-0,208^{* *}$ & $-0,252^{* *}$ \\
CQR & $0,349^{* *}$ & $0,228^{* *}$ & $-0,019$ & $-0,090$ \\
CA & $0,468^{* *}$ & $0,245^{* *}$ & $-0,009$ & $-0,153^{*}$
\end{tabular}

Nota: AD - ansiedade-depressão; ID - isolamento-depressão; QS - queixas somáticas; PS Problemas sociais; PP - problemas de pensamento; PA - problemas de atenção; CQR comportamento de quebrar regras; $\mathrm{CA}-$ comportamento agressivo; $* \mathrm{p}<0,05 ; * * \mathrm{p}<0,01$.

Com vistas a pormenorizar os resultados das análises de correlação, foram implementadas regressões lineares múltiplas (método enter) para investigar a relação entre o clima familiar e os problemas de comportamento das crianças (Tabela 3). Foram inseridos todos os fatores do ICF, inclusive os que não apresentaram correlações significativas, uma vez que a inserção de todas as variáveis em um único modelo pode apresentar padrões diferentes de associações.

\section{TABELA 3:}

Análises de regressão linear múltipla (método enter) do ICF nos fatores do CBCL

\begin{tabular}{llccccccc}
\hline Variáveis & & \multicolumn{2}{c}{$\begin{array}{c}\text { Coeficientes não- } \\
\text { padronizados }\end{array}$} & $\begin{array}{c}\text { Coeficientes } \\
\text { padronizados }\end{array}$ & \multirow{t}{*}{ Sig. } & \multirow{2}{*}{$\boldsymbol{R}^{\mathbf{2}}$} \\
\cline { 3 - 7 } & & B & Erro-padrão & Beta & & & \\
\hline \multirow{3}{*}{ Ansiedade- } & Constante & 0,08 & 0,16 & -- & 0,50 & 0,62 & \\
Depressão & Conflito & 0,12 & 0,03 & 0,30 & 3,86 & 0,00 & \\
& Hierarquia & 0,01 & 0,03 & 0,03 & 0,36 & 0,72 & 0,09 \\
& Apoio & 0,02 & 0,04 & 0,03 & 0,43 & 0,67 & \\
& Coesão & 0,00 & 0,04 & 0,01 & 0,07 & 0,94 & \\
\hline
\end{tabular}




\section{TABELA 3:}

Análises de regressão linear múltipla (método enter) do ICF nos fatores do CBCL (continua)

\begin{tabular}{|c|c|c|c|c|c|c|c|}
\hline \multirow[t]{2}{*}{ Variáveis } & & \multicolumn{2}{|c|}{$\begin{array}{l}\text { Coeficientes não- } \\
\text { padronizados }\end{array}$} & \multirow{2}{*}{$\begin{array}{c}\begin{array}{c}\text { Coeficientes } \\
\text { padronizados }\end{array} \\
\text { Beta } \\
\end{array}$} & \multirow[t]{2}{*}{$t$} & \multirow[t]{2}{*}{ Sig. } & \multirow[t]{2}{*}{$R^{2}$} \\
\hline & & B & Erro-padrão & & & & \\
\hline \multirow{5}{*}{$\begin{array}{l}\text { Isolamento- } \\
\text { Depressão }\end{array}$} & Constante & 0,34 & 0,13 & -- & 2,52 & 0,01 & \multirow{5}{*}{0,04} \\
\hline & Conflito & 0,01 & 0,03 & 0,03 & 0,40 & 0,69 & \\
\hline & Hierarquia & 0,05 & 0,03 & 0,14 & 1,87 & 0,06 & \\
\hline & Apoio & $-0,04$ & 0,03 & $-0,12$ & $-1,52$ & 0,13 & \\
\hline & Coesão & $-0,03$ & 0,03 & $-0,08$ & $-0,91$ & 0,36 & \\
\hline \multirow{5}{*}{$\begin{array}{l}\text { Queixas } \\
\text { somáticas }\end{array}$} & Constante & 0,41 & 0,12 & -- & 3,30 & 0,00 & \multirow{5}{*}{0,10} \\
\hline & Conflito & 0,03 & 0,02 & 0,11 & 1,41 & 0,16 & \\
\hline & Hierarquia & 0,03 & 0,02 & 0,10 & 1,38 & 0,17 & \\
\hline & Apoio & $-0,04$ & 0,03 & $-0,11$ & $-1,35$ & 0,18 & \\
\hline & Coesão & $-0,05$ & 0,03 & $-0,16$ & $-1,87$ & 0,06 & \\
\hline \multirow{5}{*}{$\begin{array}{l}\text { Problemas de } \\
\text { sociais }\end{array}$} & Constante & $-0,02$ & 0,13 & -- & $-0,19$ & 0,85 & \multirow{5}{*}{0,13} \\
\hline & Conflito & 0,11 & 0,03 & 0,31 & 4,08 & 0,00 & \\
\hline & Hierarquia & 0,03 & 0,03 & 0,09 & 1,32 & 0,19 & \\
\hline & Apoio & $-0,03$ & 0,03 & $-0,07$ & $-0,89$ & 0,37 & \\
\hline & Coesão & 0,02 & 0,03 & 0,06 & 0,74 & 0,46 & \\
\hline \multirow{5}{*}{$\begin{array}{l}\text { Problemas de } \\
\text { pensamento }\end{array}$} & Constante & 0,07 & 0,10 & -- & 0,74 & 0,46 & \multirow{5}{*}{0,10} \\
\hline & Conflito & 0,07 & 0,02 & 0,30 & 3,80 & 0,00 & \\
\hline & Hierarquia & 0,00 & 0,02 & 0,02 & 0,23 & 0,82 & \\
\hline & Apoio & $-0,03$ & 0,02 & $-0,09$ & $-1,15$ & 0,25 & \\
\hline & Coesão & 0,01 & 0,02 & 0,03 & 0,31 & 0,75 & \\
\hline \multirow{5}{*}{$\begin{array}{l}\text { Problemas de } \\
\text { atenção }\end{array}$} & Constante & 0,32 & 0,18 & -- & 1,78 & 0,08 & \multirow{5}{*}{0,22} \\
\hline & Conflito & 0,18 & 0,04 & 0,36 & 5,00 & 0,00 & \\
\hline & Hierarquia & 0,05 & 0,04 & 0,10 & 1,50 & 0,14 & \\
\hline & Apoio & $-0,08$ & 0,04 & $-0,15$ & $-2,11$ & 0,04 & \\
\hline & Coesão & $-0,01$ & 0,04 & $-0,02$ & $-0,19$ & 0,85 & \\
\hline \multirow{5}{*}{$\begin{array}{l}\text { Comportamento } \\
\text { de quebrar } \\
\text { regras }\end{array}$} & Constante & $-0,08$ & 0,07 & -- & $-1,13$ & 0,26 & \multirow{5}{*}{0,13} \\
\hline & Conflito & 0,06 & 0,01 & 0,33 & 4,29 & 0,00 & \\
\hline & Hierarquia & 0,01 & 0,01 & 0,07 & 0,95 & 0,34 & \\
\hline & Apoio & 0,00 & 0,02 & 0,00 & 0,00 & 1,00 & \\
\hline & Coesão & 0,01 & 0,02 & 0,04 & 0,51 & 0,61 & \\
\hline \multirow{5}{*}{$\begin{array}{l}\text { Comportamento } \\
\text { agressivo }\end{array}$} & Constante & $-0,19$ & 0,18 & -- & $-1,08$ & 0,28 & \multirow{5}{*}{0,22} \\
\hline & Conflito & 0,22 & 0,03 & 0,47 & 6,43 & 0,00 & \\
\hline & Hierarquia & 0,00 & 0,04 & 0,01 & 0,14 & 0,89 & \\
\hline & Apoio & 0,04 & 0,04 & 0,07 & 0,91 & 0,37 & \\
\hline & Coesão & $-0,01$ & 0,04 & $-0,01$ & $-0,14$ & 0,89 & \\
\hline
\end{tabular}

Em relação ao fator ansiedade-depressão, o ICF explicou 9\% de sua variância. Apenas o fator conflito apresentou predição estatisticamente significativa $(\beta=0,30, p<0,01)$. Para o fator isolamento-depressão, o ICF explicou $4 \%$ da 
variância, sendo que apenas o fator hierarquia apresentou impacto marginalmente significativo $(\beta=0,14, p=0,06)$. Em relação às queixas somáticas, $10 \%$ da variância foi explicada, mas apenas $\mathrm{o}$ fator coesão apresentou impacto marginalmente significativo $(\beta=-0,16, \mathrm{p}=0,06)$. Em relação aos problemas sociais, o ICF explicou $13 \%$ de sua variância, mas apenas o fator conflito teve impacto estatisticamente significativo $(\beta=0,31, \mathrm{p}<0,01)$. Em relação aos problemas de pensamento, o ICF explicou $10 \%$ da variância, mas apenas o fator conflito impactou significativamente $(\beta=0,30, \mathrm{p}<0,01)$. Para problemas de atenção, o ICF explicou $22 \%$ da variância, sendo que conflito impactou positivamente $(\beta=0,36, \mathrm{p}<0,01)$ e apoio impactou negativamente $(\beta=-0,15, \mathrm{p}<$ 0,05). Para comportamento de quebrar regras, o ICF explicou $13 \%$ da variância, mas apenas conflito impactou significativamente $(\beta=0,33, \mathrm{p}<0,01)$. Por fim, em relação ao comportamento agressivo, o ICF explicou $22 \%$ da variância, sendo que, mais uma vez, apenas conflito apresentou impacto estatisticamente significativo ( $\beta$ $=0,47, \mathrm{p}<0,01)$.

\section{3}

\section{Discussão}

Os resultados do presente estudo indicaram correlações significativas entre as características sociodemográficas avaliadas e pelo menos um dos fatores do clima familiar. Pais com maiores níveis de escolaridade e com maior renda familiar apresentaram maior apoio e coesão familiar. Levy e Jonathan (2010) sugerem que pais com maiores níveis de escolaridade apresentam mais recursos e maior participação na vida extracurricular das crianças, além de menos conflitos no ambiente familiar. Famílias cujas mães apresentam maior nível de escolaridade, contam com mais recursos culturais e ambientais que contribuem para o desenvolvimento das crianças (FERREIRA; BARREIRA, 2010).

Além disso, Grzybowski e Wagner (2010) demonstraram que as condições financeiras dos pais contribuem para relações saudáveis com seus filhos. Portanto, quanto mais recursos familiares, menor tende a ser o estresse parental e o conflito familiar (PETRUCCI et. al., 2016). Por outro lado, a baixa renda familiar pode 
afetar os recursos físicos da família, influenciando os recursos emocionais dos seus membros (ROHENKOHL; CASTRO, 2012).

A partir de um entendimento sistêmico e bioecológico, os indivíduos são compreendidos como parte do microssistema familiar que, por sua vez, faz parte de um contexto sociocultural mais amplo. Faz sentido, portanto, compreender as relações familiares e a saúde mental de seus membros, sofrendo influências das relações externas a esse microssistema, como a excesso de recursos que muitas famílias possuem, influenciando o desenvolvimento das crianças (MARTINS; SZYMANSKI, 2004; DE ANTONI et. al.,2009)

Neste estudo, verificou-se que quanto pior a qualidade da saúde mental dos pais, maior o conflito e a hierarquia familiar e menor o apoio e a coesão. A saúde mental materna apresentou correlações mais elevadas com as dimensões do clima familiar, com exceção da dimensão hierarquia. Para Tavares, Lobo et. al. (2010) e Borsa e Nunes (2008), a mãe ainda exerce um papel de maior importância do que o pai no desenvolvimento da criança. Embora o presente estudo avalie apenas a relação da saúde mental dos pais com a qualidade do clima familiar, esses resultados podem estar associados à diferença entre o vínculo materno e paterno existente na maioria das famílias. Além disso, Squassoni et. al. (2014) demonstraram que crianças com sintomas emocionais e problemas de conduta apresentaram menor apoio familiar do que crianças com ausência de tais características, o que vai ao encontro dos resultados do presente estudo.

Crianças que repetiram de ano na escola apresentaram maior índice de conflito familiar e menor índice de coesão familiar do que crianças que não repetiram. De acordo com o estudo de Rohenkohl e Castro (2012), a qualidade das relações familiares pode ser um fator de proteção contra o surgimento de problemas psicológicos e também cognitivos. O apoio e a interação dentro do seio da família contribuem para a criança desenvolver suas habilidades e competências, resultando em ferramentas para a adaptação e o enfrentamento dos desafios da vida (LEVY; JONATHAN, 2010. MATOS et. al., 2014. OSTI, 2016. PIRES; SILVA; ASSIS, 2012. PORTUGAL; ALBERTO, 2013. SQUASSONI et. al., 2014).

Vale destacar que a coesão familiar teve efeito alto na comparação dos dois grupos, indicando que a união familiar teve forte influência no desempenho escolar das crianças. Os primeiros processos proximais acontecem no ambiente familiar e, por isso, as interações familiares e as características emocionais e afetivas dos 
membros da família são fundamentais para o desenvolvimento de competências sociais da criança (BORSA; PETRUCCI; KOLLER, 2015).

$\mathrm{O}$ apoio familiar relaciona-se com o suporte material e emocional recebido dentro de casa (TEODORO et. al., 2009). O apoio ou suporte familiar manifesta-se no carinho, cuidado, comunicação, regras claras e coerentes, e valorização das atitudes das crianças, favorecendo a autonomia dos mesmos e o sentimento de pertença que ajuda as crianças ao enfrentarem situações adversas. Desta forma, o apoio e a coesão familiar contribuem de forma a facilitar o diágolo, a relação conjugal saudável e a liderança compartilhada com os filhos de forma democrática e não coerciva (SOUZA; BAPTISTA; ALVES, 2008).

Os resultados do presente estudo indicaram, ainda, que crianças com pais separados apresentaram maiores índices de conflito e menores índices de coesão do que as crianças cujos pais não eram separados. Esses resultados também foram encontrados em outras pesquisas semelhantes. Nave e Jesus (2005) e Portugal e Alberto (2013) constataram que a maioria das crianças vivenciam o divórcio dos pais de forma negativa, principalmente quando os genitores não conseguem se comunicar de forma clara, ocasionando conflitos. Além disso, as crianças que não passam por um processo de divórcio, podem apresentar mais habilidades sociais e menos problemas comportamentais que crianças de famílias recasadas (LEME; MARTURANO; FONTAINE, 2014).

Grzybowski e Wagner (2010), ao estudarem sobre a educação dos filhos pós-divórcio, destacam que a presença de conflitos conjugais acaba acarretando dificuldades em relação a educação e coesão familiar. Polleto e Koller (2008), ao utilizarem o olhar bioecológico de Bronfrenbrenner, destacam que o divórcio na família pode ser um fator de risco, caso se torne um evento estressor, ou seja, causador de conflitos familiares.

As crianças que haviam realizado tratamento psicológico apresentaram maiores índices de conflito familiar em comparação às crianças que não haviam realizado tratamento. Sá et. al. (2010) afirmam que crianças com transtornos mentais são reflexos de pais com problemas em sua saúde mental. Sugere-se, portanto, que esses problemas são intergeracionais, associando-se a altos níveis de conflitos familiares.

Ao investigar a relação entre os fatores do ICF e os problemas emocionais e comportamentais das crianças avaliados pelo CBCL, verificou-se que o fator 
conflito familiar foi o que apresentou maior associação com os problemas emocionais/comportamentais das crianças. O conflito existente no ambiente familiar é caracterizado por sentimentos negativos que podem ocasionar estresse e agressividade (ROHENKOHL; CASTRO, 2012). Dessa forma, crianças inseridas em ambientes familiares conflituosos podem encontrar dificuldades nas relações interpessoais e no desenvolvimento das suas características individuais (PETRUCCI et. al., 2016). Além disso, dentre as associações do conflito familiar com os problemas na infância avaliados, houve maior correlação com a agressividade, corroborando com estudos que indicaram associação da punição e agressão entre os membros da família, conflitos familiares e agressividade infantil (FERREIRA; MARTURANO, 2002. SILVEIRA; WAGNER, 2011. BORSA; BANDEIRA, 2014).

Pais que utilizam práticas educativas agressivas ou coercitivas promovem comportamentos agressivos nas crianças, reforçando os mesmos padrões de respostas (DEL PRETTE; DEL PRETTE, 2005). Algumas atitudes dos pais, como gritar e bater quando a criança emite comportamentos indesejáveis, pode servir de modelo para que as crianças se comportem agressivamente. Por outro lado, famílias que estimulam comportamentos pró-sociais (Bolsoni-Silva \& Marturano, 2002), diálogo familiar (PORTUGAL; ALBERTO, 2013) e uma relação afetuosa entre os membros da família (D’AVILA-BACARJ; MARTURANO; ELIAS, 2005) tendem a favorecer o desenvolvimento social de seus filhos.

Em geral, observa-se que o clima familiar negativo (conflito e hierarquia) apresentou correlações positivas com os problemas emocionais/comportamentais das crianças. Já o clima familiar positivo (coesão e apoio) apresentou correlação negativas com esses problemas. As análises de regressão indicaram que o fator conflito foi o único que apresentou efeito significativo na ocorrência da maior parte dos problemas emocionais e comportamentais, com exceção dos problemas de isolamento-depressão e de queixas somáticas. O fator apoio social teve efeito significativo apenas sobre os problemas de atenção, mas a variância explicada foi inferior à variância explicada pelo fator conflito.

Esses resultados ratificaram os dados das análises de correlação já citadas, indicando uma maior associação entre conflito familiar e problemas emocionais e comportamentais. $\mathrm{O}$ conflito familiar está associado à falta de vínculos positivos entre os membros da família, a qual ocasiona problemas comportamentais e 
emocionais e resulta em baixo rendimento escolar, dificuldades de concentração, problemas de memória e comportamentos hiperativos (MATOS et. al., 2014).

Ao avaliar a relação preditiva entre clima familiar e indicadores de adaptação psicológica em adolescentes, Sbicigo e Dell'Aglio (2012) concluíram que altos índices de apoio e de coesão e baixos índices de conflito na família foram considerados como preditores de autoestima e de auto eficácia geral nos adolescentes do estudo. Entretanto, por se tratar de um estudo transversal, as autoras destacaram não ser possível afirmar a existência de uma relação causal entre as variáveis.

O modelo bioecológico considera o microssistema familiar como fonte de segurança e apoio para a criança se desenvolver de forma saudável. Porém, muitas vezes os processos proximais que acontecem nesse sistema podem ser disfuncionais devido aos eventos de vida estressantes (BRONFENBRENNER, 1996). Segundo Petrucci et. al. (2016), crianças que vivem em ambientes familiares que oferecem suporte às suas necessidades socioemocionais geralmente se adaptam mais facilmente a novos contextos, apresentando maiores níveis de competência social e menores níveis de problemas comportamentais. O modelo bioecológico de Bronfenbrenner contribui ao sugerir que as características familiares estão associadas às habilidades ou dificuldades sociais no indivíduo (BROFENBRENNER; MORRIS, 1998), conforme pode ser observado no presente estudo.

A partir dos resultados encontrados nas correlações do ICF com as características sociodemográficas e familiares, notou-se a importância da realização de novos estudos, com outros instrumentos e amostras para que tais relações sejam elucidadas. 


\section{Considerações finais}

Este estudo teve por objetivo verificar a relação do clima familiar com os problemas emocionais e comportamentais das crianças em uma amostra de crianças da cidade do Rio de Janeiro. A escolha por esse tema surge da relevância da família enquanto primeiro ambiente de interação da criança. Conforme propõe o modelo bioecológico do desenvolvimento humano, cada contexto em que o indivíduo está inserido apresenta características importantes, refletindo no comportamento das pessoas. A partir deste objetivo e desse olhar teórico, buscou-se investigar diferentes variáveis associadas às famílias e às crianças.

Com base nos resultados obtidos, verifica-se associações significativas entre o clima familiar e os problemas emocionais/comportamentais das crianças. Nota-se que as características do clima familiar, como conflito, hierarquia, apoio e coesão, podem configurar como importantes fatores de risco ou de proteção para o desenvolvimento infantil. Os fatores positivos do clima familiar (apoio e coesão) relacionaram-se negativamente com os problemas infantis. Já os fatores negativos relacionaram-se positivamente com tais problemas. Desta forma, acredita-se que a qualidade de seus processos proximais, como o tipo de clima familiar que predomina entre os membros da família, influencia os comportamentos e emoções das crianças.

Assim, conclui-se que as diversas famílias que vivenciam conflitos entre os seus membros acabam enfrentando problemas em relação à adaptação das crianças em outros contextos. Além disso, o conflito familiar resulta no afastamento dos membros desse núcleo, causando consequências negativas para família no decorrer do ciclo vital (MINUCHIN,1990). Como apontado neste estudo, famílias com altos níveis de conflito e hierarquia e baixos níveis de apoio e coesão podem apresentar associação com problemas emocionais e comportamentais das crianças.

No caso de crianças com dificuldades ou queixas escolares, pode-se concluir que, em muitos casos, os problemas presentes na escola estão diretamente ligados ao ambiente familiar (TEIXEIRA, et. al., 2014). Bronfenbrenner (1996) afirmou que os processos proximais, como as díades no contexto familiar, servem como experiência para as crianças quando estas forem interagir fora desse contexto. 
Portanto, problemas cognitivos, comportamentais e emocionais - relatados muitas vezes por professores na contemporaneidade e, em muitos casos, mal conduzidos pela sociedade - podem ter suas causas dentro do seio familiar da criança (TEIXEIRA, et. al., 2014).

Outro dado para refletir é a relação negativa entre os construtos apoio e coesão familiar com a presença de problemas emocionais e comportamentais na infância. Portanto, famílias com suporte emocional e interação afetuosa, tendem a proporcionar um adequado espaço de crescimento e encorajamento para os pequenos enfrentarem os desafios da vida em sociedade. Assim sendo, os pesquisadores são levados a olhar e utilizar a família como principal agente no desenvolvimento infantil. Minuchin (1990), reconhecido teórico e terapeuta familiar, afirmou que trabalhar a estrutura familiar, as características familiares presentes e oportunizar a comunicação entre os seus membros gera união familiar e favorece a resolução dos conflitos dentro e fora desse contexto.

Contudo, faz-se importante destacar algumas limitações do presente estudo. O estudo foi realizado na cidade do Rio de Janeiro e em área do chamado Grande Rio, limitando-se o mesmo, portanto, ao perfil e cultura das famílias dessas localidades. Outro ponto a se destacar é o fato dos questionários terem sido respondidos pelos cuidadores sem a presença de pesquisadores, podendo ter ocorrido variáveis que influenciaram nas respostas aos questionamentos feitos, além do fato de que somente um dos responsáveis foi consultado, limitando-se a percepção a apenas um membro da família.

Os resultados do presente estudo, que vêm ao encontro das pesquisas das últimas décadas, sinalizam fortemente a importância de trabalhar com as famílias (TEODORO; ALLGAYER; LAND, 2009; DIAS, 2011; VALENCIA; LOPEZ, 2011; BORSA;BANDEIRA, 2014; PETRUCCI; BORSA; KOLLER, 2016). Portanto, sugere-se com os resultados obtidos, que as futuras pesquisas cientificas, assim como profissionais que vivenciam a prática em consultórios, escolas, comunidades, compreendam os problemas emocionais e comportamentais na infância a partir de um olhar sistêmico, ou seja, entendendo os diferentes sistemas que o indivíduo está inserido, dentre eles a família. Vale destacar que os dados obtidos contribuem para a valorização do contexto familiar como potencializador do desenvolvimento infantil, já que é nessa interação com os membros que as crianças iniciam a construção de suas capacidades sociais e emocionais. 
Por fim, levando em conta a escassez do número de obras sobre o tema clima familiar, ressalta-se a importância da realização de novos estudos, quantitativos e qualitativos, os quais busquem integrar as percepções do clima familiar de todos os membros presentes nesse ambiente e, assim, possibilitem um trabalho com dados representativos, bem como a obtenção de resultados relevantes. Desta forma, podemos esperar resultados que proporcionem aos profissionais e à sociedade, de um modo geral, a trabalhar a família como sendo a fonte potencial e primordial do desenvolvimento infantil, a fim de reduzir os prejuízos decorrentes dos relacionamentos familiares negativos, aumentando os benefícios dos relacionamentos familiares positivos sobre o desenvolvimento na infância. 


\section{Referências bibliográficas}

ACHENBACH, T. M. (2001). Manual for the Child Behavior Checklist/6-18 and 2001 profile. Burlington: University of Vermont.

ANDRADE, Susanne Anjos et al. Ambiente familiar e desenvolvimento cognitivo infantil: uma abordagem epidemiológica. Rev. Saúde Pública [online]. 2005, vol.39, n.4, pp.606-611. ISSN 1518-8787. Disponível em: $<$ http://dx.doi.org/>.

ANSELMI, L.; FLEITLICH-BILYK, et. al. Prevalence of psychiatric disorders in a Brazilian birth cohort of 11-year-olds. Social Psychiatry and Psychiatric Epidemiology. vol. 45(1), pp. 135 - 142. 2010.

ASSIS, S.G.; AVANCI, J. Q. A.; OLIVEIRA, R. V. C. Desigualdades socioeconômicas e saúde mental infantil. Revista Saúde Pública, vol. 43(1), pp. 92 - 100. São Paulo: Universidade de São Paulo, 2009.

BANDEIRA, D. R.; BORSA, J. B., et. al. Avaliação de problemas de comportamento infantil através do Child Behavior Checklist (CBCL). In: HUTZ, C. S. (Org.). Avanços em Avaliação Psicológica e Neuropsicológica de crianças e adolescentes, pp. 101-122. São Paulo: Casa do Psicólogo, 2010.

BAPTISTA, M. N.; OLIVEIRA, A. A. Sintomatologia de depressão e suporte familiar em adolescentes: um estudo de correlação. Revista Brasileira de Crescimento e Desenvolvimento Humano. vol. 14 (3), pp. 58 - 67. São Paulo: 2004.

BAPTISTA, M. N.; TEODORO, M. L. M. Psicologia de família: teoria, avaliação e intervenção. Porto Alegre: Artmed, 2012.

BARNETT, R. A.; HUNTER, M. Adjustment of siblings of children with mental health problems: behaviour, self-concept, quality of life and family functioning. Journal Child Family Study. vol. 21, pp. 262 - 272. Augusta: 2012.

BENNETT, J.; GRIMLEY, L. Parenting in the Global Community: Ass - cultural / International perspective. In: FINE, M.; LEE, S. (Eds.). Handbook of diversity in 88 Parent Education: the changing faces of Parenting and Parent education (pp. 97 - 132). USA: Academic Press, 2011.

BENETTI, S. P. C. Conflito Conjugal: Impacto no Desenvolvimento Psicológico da Criança e do Adolescente. In: Psicologia: Reflexão e Crítica. vol. 19(2), pp. 261 - 268. Porto Alegre: UFRGS, 2006.

BERTAlanfFy, L. V. Teoria Geral dos Sistemas. Rio de Janeiro: Edições, 1973.

BOING, E.; CREPALDI, M. A.; MORÉ, C. L. Pesquisas com famílias: Aspectos teórico-metodológicos. In: Paidéia. vol. 18(40), pp. 251 - 266. São Paulo: 2008. 
BOLSONI-SILVA, A. T.; DEL PRETTE, A. Problemas de comportamento: um panorama da área. In: Revista Brasileira de Terapia Comportamental e Cognitiva. vol. 5(2), pp. 91 - 103. Ribeirão Preto: Universidade de São Paulo, 2003.

BOLSONI-SILVA, A. T.; MATURANO, E. M. Práticas educativas e problemas de comportamento: Uma análise a luz das habilidades sociais. In: Estudos de Psicologia. vol. 7(2), pp. 227 - 235. Rio Grande do Norte: 2002.

BORDIN, I.A., DUARTE, C.S. et. al.. Severe physical punishment: risk of mental health problems for poor urban children in Brazil. In: Bull World Health Organ. vol. 87(5), pp. 336 - 344. Genebra: 2009.

BORSA, J. C.; BANDEIRA, D. R. Comportamentos Agressivos na Infância: Da teoria à prática. Porto Alegre: Casa do Psicólogo, 2014.

BORSA, J. C.; NUNES, M. L. Concordância parental sobre problemas de comportamento infantil através do CBCL. In: Paidéia. vol. 18(40), pp. 317 - 330. São Paulo: 2008.

BORSA, J. C.; NUNES, M. L. Prevalência de problemas de comportamento em uma amostra de crianças em idade escolar da cidade de Porto Alegre. Aletheia. vol. 34(11), pp. 32 - 42. Canoas: 2011.

BORSA, J. C.; PETRUCCI, G. W.; KOLLER, S. H. A participação dos pais nas pesquisas sobre bullying escolar. In: Revista Quadrimestral da ABRAPEE. vol. 19(1), pp. 41 - 48. São Paulo: 2015.

BORSA, J. C.; SOUZA, D. S.; BANDEIRA, D. R. Prevalência dos problemas de comportamentos em uma amostra de crianças do Rio Grande do Sul. In: Psicologia: Teoria e Prática. 13(2), 15-29. Rio Grande do Sul: 2011.

BRONFENBRENNER, U. A Ecologia do Desenvolvimento Humano: Experimentos Naturais e Planejados. Porto Alegre: Artes Médicas, 1996.

BRONFENBRENNER, U.; MORRIS, P. A. The ecology of developmental processes. In: DAWON, W.; LERNER, R. M (Orgs.). Handbook of child psychology. Vol. 1(5), pp. 993 - 1028. 1998.

CARTER, B.; MCGOLDRICK, M. As mudanças no ciclo familiar: uma estrutura para a Terapia Familiar. In: CARTE, B; MCGOLDRICK, M (org.). As mudanças no ciclo de vida familiar - uma estrutura para a terapia familiar. pp. 7 - 27. Porto Alegre: Artmed, 2011.

CID, M. F. B.; MATSUKURA, T. S.; SILVA, M. D. P. Transtorno Mental Materno e Desenvolvimento Infantil: percepções sobre a realidade. In: Mundo da Saúde. vol. 36(2), pp. 265 - 275. São Paulo: 2012.

COUTINHO, M. Apoio à família e formação parental. In: Análise Psicológica. vol. 1, pp. 55 - 64. Lisboa: 2004. 
D’AVILA-BACARJI, K. M. G.; MARTURANO, E. M.; ELIAS, L. C. S. Suporte parental: um estudo sobre crianças com queixas escolares. In: Psicologia em Estudo. vol. 10(1), pp. 107 - 115. São Paulo: 2005.

DE ANTONI, C.; TEODORO, M. L. M.; KOLLER, S. H. Coesão e Hierarquia em famílias fisicamente abusivas. In: Universitas Psychologica. vol. 8 (2), pp. 399 411. Bogotá: 2009.

DEL PRETTE A.; DEL PRETTE, Z. A. P. Psicologia das relações interpessoais: Vivências para o trabalho em grupo. Petrópolis: Vozes, 2001.

DEL PRETTE A.; DEL PRETTE, Z. A. P. Psicologia das Habilidades Sociais na Infância: teoria e prática. Petrópolis: Vozes, 2005.

DESSEN, M. A. Estudando a família em desenvolvimento: Desafios conceituais e teóricos. In: Psicologia: Ciência e Evolução. vol. 30(núm. esp.), pp. 202 - 219. Brasília: 2010

DESSEN, M. A.; POLONIA, A. C. A Família e a Escola como Contextos de Desenvolvimento Humano. In: Paidéia. vol. 17 (36), pp. 21 - 32. São Paulo: 2007.

DESSEN, M. A.; SZELBRACIKOWSKI, A. C. Estabilidades e mudanças em padrões familiares de crianças com problemas de comportamento exteriorizado. In: Paidéia. vol. 16(33), pp. 71 - 80. São Paulo: 2006

DIAS, M. O. Um olhar sobre a família e perspectiva sistêmica: O processo de comunicação no sistema familiar. In: Gestão e Desenvolvimento. vol. 19, pp. 139 - 156. São Carlos: 2011.

DINIZ, E.; KOLLER, S. H. O afeto como um processo de desenvolvimento ecológico. In: Educar em Revista. vol. 36, pp. 65 - 76. Paraná: 2010.

FERREIRA, M. T.; MATURANO, E. M. Ambiente familiar e os problemas do comportamento apresentados por crianças com baixo desempenho escolar. In: Psicologia e Reflexão. vol. 5(1), pp. 35 - 44. Porto Alegre: 2002

FERREIRA, S. H. A.; BARREIRA, S. D. Ambiente familiar e aprendizagem escolar de alunos de educação infantil. In: Psico. vol. 41(4), pp. 462 - 472. Porto Alegre: 2010.

FONSECA, C. Concepções de família e práticas de intervenção: uma contribuição antropológica. In: Saúde e Sociedade. Vol. 14, n. 2, pp. 50 - 59. Porto Alegre: 2005.

GONCALVES, E. S.; MURTA, S. G. Avaliação dos efeitos de uma modalidade de treinamento de habilidades sociais para crianças. In: Psicologia: Reflexão e Crítica.vol. 21, n. 3, pp. 430 - 436. Porto Alegre: UFRGS, 2008. 
GREENBERG, M. T.; DOMITROVICH, C.; BUMBARGER, B. The prevention of mental disorders in school-aged children: Current state of the field. In: Prevention and Treatment. vol. 4, pp. 1 - 59. 2001.

GRZYBOWSKI, L. S.; WAGNER, A. Casa do Pai, Casa da Mãe: A coparentalidade após o divórcio. In: Psicologia: Teoria e Pesquisa. vol. 26(1), pp. 77 - 87. Brasília: Universidade de Brasília, 2010.

HAUKOOS, J. S.; LEWIS, R. J. Advanced statistics: Bootstrapping confidence intervals for statistics with "difficult" distributions. In: Academic Emergency Medicine.vol. 12(4), pp. 360 - 365. 2005.

HOMEM, T. C.; GASPAR, M. S., et. al. Perturbações de comportamento externalizante em idade pré-escolar: O caso específico da perturbação de oposição. In: Análise Psicológica. vol. 31(1), pp. 31 - 48. Lisboa: ISPA, 2013.

KREPPNER, K. The child and the family: Interdependence in developmental pathways. In: Psicologia: Teoria e Pesquisa. vol. 16(1), pp. 11 - 22. Brasília: Universidade de Brasília, 2000.

LA TAILLE., Y. Prefácio. In: PIAGET, J. A construção do real na criança. $3^{\mathrm{a}} \mathrm{ed}$. São Paulo: Editora Ática, 2003.

LEME, V. B.; MARTURANO, E. M.; FONTAINE, A. M. Habilidades sociais, problemas de comportamento e competência acadêmica de crianças de famílias nucleares e recasadas. In: Estudos e Pesquisas em Psicologia. vol. 14(3), pp. 854 - 876. Rio de Janeiro: UERJ, 2014.

LEVY, L.; JONATHAN, E. G. Minha família é legal? A família do imaginário infantil. In: Estudos em Psicologia, vol. 27(1), pp. 49 - 56. Campinas: 2010.

LINS, T.; ALVARENGA, P. et.al. Problemas Externalizantes e Agressividade Infantil: uma revisão de estudos brasileiros. In: Arquivos Brasileiros de Psicologia. pp. 57 - 75, 2012.

LISBOA, C. S.; KOLLER, S. H. Construção e Validação de Conteúdo da Escala de Percepção de Professores dos Comportamentos Agressivos de Crianças na Escola. In: Psicologia em Estudo. pp. 59 - 69, Rio Grande do Sul: 2001.

MAIA, J. M. D.; WILLIAMS, L. C. A. Fatores de risco e fatores de proteção ao desenvolvimento infantil: uma revisão da área. In: Temas em Psicologia. vol. 13, no 2, pp. 91 - 103. São Carlos: 2005.

MARTINS, E.; SZYMANSKI, H. A Abordagem Ecológica de Urie Brofrenbrenner em Estudos com Famílias. Estudos e Pesquisas. Rio de Janeiro: Universidade Federal do Estado do Rio de Janeiro, 2004.

MATOS, M. B., CRUZ, A. C., et. al. Eventos estressantes na família e indicadores de problemas de saúde mental em crianças com idade escolar. In: Ciência \& Saúde Coletiva. vol. 20(7), pp. 2157-2163. Rio de Janeiro: 2014. 
MENEGUEL, S. N.; GIUGLIANI, E. J.; FALCETO, O. Relações entre Violência Doméstica e Agressividade na Adolescência. In: Caderno de Saúde Pública, pp.327 - 335. Rio de Janeiro: 1998.

MERG, M. M. G. Características da clientela infantil em clínicas-escola. Dissertação de Mestrado. Programa de estudos em Psicologia, Pontifícia Universidade Católica do Rio Grande do Sul. Rio Grande do Sul: 2008.

MINUCHIN, S. Famílias: funcionamento e tratamento. Porto Alegre: Artes Médicas, 1982.

MINUCHIN, S. Técnicas de terapia familiar. Porto Alegre: Artes Médicas, 1990.

MINUCHIN, S. A cura da família: Histórias de esperança e renovação contadas pela terapia familiar. Porto Alegre: Artes Médicas, 1995.

MINUCHIN, S.; NICHOLS, M. P.; LEE, W. Famílias e Casais: do sintoma ao sistema. Porto Alegre: Artmed, 2009.

MOOS, R. H. Family environment scale. Palo Alto, CA: Consulting Psychologist' Press, 1974.

NAVE, F. J.; JESUS, S. N. Ameaças ao funcionamento familiar: Uma perspectiva sistêmica da cultura organizacional da(s) família(s). In: Educação. 30(1), 11-26. Rio Grande do Sul: Universidade de Santa Maria, 2005.

NICHOLS, M. P.; SCHWARTZ, R. C. Terapia Familiar: conceitos e métodos. Porto Alegre: Artmed, 2007.

OSTI, A. Contexto familiar e o desempenho de estudantes do $5^{\circ}$ ano de uma escola no interior de São Paulo. In: EDT - Educ. Temat. Digit. vol. 18(2), pp. 369 - 383. Campinas: 2016.

PEDRINI, J. R.; FRIZZO, G. B. Avaliação de indicadores de problemas de comportamento infantil relatados por pais e professores. In: Aletheia. $\mathrm{n}^{\mathbf{o}} 33$. Canoas: 2010

PETRUCCI, G. W.; BORSA, J. C.; KOLLER, S. H. A família e a escolar no desenvolvimento socioemocional na infância. In: Temas em Psicologia. vol. 24(2), pp. 391 - 402. Porto Alegre: 2016.

PIRES, T. O.; SILVA, C. M.; ASSIS, S. G. Ambiente familiar e transtorno de déficit de atenção e hiperatividade. In: Revista de Saúde Pública. vol. 46(4), pp. 624 - 632. São Paulo: Universidade de São Paulo, 2012.

POLETTO, M.; KOLLER, S. H. Contextos ecológicos: promotores de resiliência, fatores de risco e de proteção. In: Estudos em Psicologia. pp. 405 - 416. Campinas: 2008 . 
PORTUGAL, A. M.; ALBERTO, I. M. Caracterização da comunicação entre progenitores e filhos em idade escolar: Estudo com uma amostra portuguesa. In: Psicologia: Teoria e pesquisa. vol. 29(4), pp. 381 - 391. Brasília: Universidade de Brasília, 2013.

REICHENHEIM, M. E; HASSELMANN, M. H; MORAES, C. L. Consequências da violência familiar na saúde da criança e do adolescente: contribuições para a elaboração de propostas de ação. In: Ciência e Saúde Coletiva. vol. 4 (1), pp. 09 121. Rio de Janeiro: 1999

ROHENKOHL, L. A.; CASTRO, E. K. Afetividade, conflito familiar e problemas de comportamento em pré-escolares de famílias de baixa renda: Visão de mães e professoras. In: Psicologia: Ciência e Profissão. vol. 32(2), pp. 438 - 451. Rio Grande do Sul, 2012.

ROTHBART, M. K.; BATES, J. E. Temperament. In: DAMON, W et. al. (Eds.), Handbook of child psychology, vol. 3. Social, emotional, and personality development (6th ed., pp. 99 - 166). New York: Wiley, 2006.

SÁ, D. G.; BORDIN, I. A., et. al. (2010). Fatores de risco para problemas de saúde mental na infância/adolescência. In: Psicologia: Teoria e Pesquisa. vol. 26(4), pp. 643 - 652. Brasília: Universidade de Brasília, 2010.

SAUR, A. M. et. al. Variables associated with cognitive, behavioral and emotional development: a cohort of schoolchildren. In: Psico-USP. vol. 19, n. 1, pp. 131-141. São Paulo: USP, 2014. Disponível em: 〈http://www.scielo.br/>. Acesso em fev. 2017.

SBICIGO, J. B.; DELL'AGLIO, D. D. (2012). Family environment and psychological adaptation in adolescents. In: Psicologia: Reflexão e Crítica. vol. 25(3), pp. 615 - 622. Porto Alegre: UFRGS, 2012. Disponível em: <https://dx.doi.org>. Acesso em: fev. 2017.

SCHULTZ, D.; SHAW, D. S. Boys' maladaptive social information processing, family emotional climate, and pathways to early conduct problems. In: Social Development. vol. 12, pp. 440 - 460. Baltimore: 2003. Disponível em: <https://dx.doi.org/>. Acesso em: fev. 2017.

SEIDL- DE- MOURA, M. L.; MENDES, D. L. F.; PESSÔA, L. P. (org). Interação Social e Desenvolvimento. Curitiba: CRV, 2009.

SILVA, N. C. B.; NUNES, C. C.; et. al.. Variáveis da família e seu impacto sobre o desenvolvimento infantil. In: Temas em Psicologia. vol. 16, n. 2, pp. 215 - 229. Ribeirão Preto: 2008.

SILVEIRA, L. O.; WAGNER, A. A importância das relações parentais frente aos problemas de comportamento na infância: convergências teóricas. In: Interação Psicologia. vol. 15(2), pp. 219 - 228. Paraná: 2011. 
SOUZA, M. S. de; BAPTISTA, M. N.; ALVES, G. A. S. Suporte familiar e saúde mental: evidência de validade baseada na relação entre variáveis. In: Aletheia. vol. 28, pp. 32 - 44. Canoas: 2008.

SQUASSONI, C. E.; MATSUKURA, T. S.; PANÚNCIO-PINTO, M. P. Apoio social e desenvolvimento socioemocional infanto-juvenil. In: Revista de Terapia Ocupacional. vol. 25(1), pp. 27 - 35. São Carlos: USP, 2014.

SVEDIN, C. G. R.; BACK, C.; DERBACK, S. B. S. Family relations, family climate and sexual abuse. In: Nordic Journal of Psychiatry. vol. 56, pp. 355 - 362. 2002.

SZELBRACIKOWSKI, A. C.; DESSEN, M. A. Problemas de comportamento externalizado e as relações familiares: revisão de literatura. In: Psicologia em Estudo. vol. 12, n. 1, pp. 33 - 40. Maringá: 2007.

SZYMANSKI, H. A Prática Reflexiva com Famílias de Baixa Renda. In: Anais do II Seminário Internacional de Pesquisa e estudos Qualitativos. Bauru: SEPQ, 2004.

TAVARES, S. F.; LOBO, S. A., et. al. A família da criança considerada "problema" na escola. In: Revista Mineira de Enfermagem. vol. 14(1), pp. 29 - 36. Minas Gerais: 2010.

TEIXEIRA, Maria Cristina T. V. et. al. Fatores de proteção associados a problemas emocionais e comportamentais em escolares. In: Estudos psicológicos. Vol. 31, n. 4, pp. 539 - 548. Campinas: 2014. Disponível em: <https://dx.doi.org/>. Acesso em: fev. 2017.

TEODORO, M. L. Afetividade e conflito em díades familiares: avaliação com o Familiograma. In: Revista Interamericana de Psicologia. vol. 40(3), pp. 385 390. 2006.

TEODORO M. L.; ALLGAYER, M.; LAND, B. Desenvolvimento e validade fatorial do inventário do clima familiar (ICF) para adolescentes. In: Psicologia: Teoria e Prática. vol. 11(3), pp. 27 - 39. Brasília: Universidade de Brasília, 2009.

TEODORO, M. L.; CARDOSO, B. M.; FREITAS, A. C. Afetividade e conflito familiar e sua relação coma depressão em crianças e adolescentes. In: Psicologia: Reflexão e Crítica. vol. 23(2), pp. 324 - 333. Porto Alegre: UFRGS, 2010.

TEODORO, M. L. M.; CARDOSO, B. M.; PEREIRA, T. F. P. (2011). As relações familiares e os problemas emocionais e de comportamento em adolescentes. In Wagner, A e cols. (2011). Desafios Psicossocias da Família Contemporânea: pesquisa e reflexões. (pp. 140-149). Porto Alegre: Artmed.

TEODORO, M. L. M., SARAIVA, A. R. B. H. L. A.; CARDOSO, B. M. Problemas emocionais e de comportamento e clima familiar entre adolescentes e seus pais. In: Psico. Porto Alegre, PUCRS, v. 45, n. 2, pp. 168-175, abr.-jun. 2014 v. 45, n. 2, pp. 168-175, abr.-jun. 2014 
VALENCIA, L. I. V.; LÓPEZ, G. C. H. Relaciones entre el clima social familiar y el desempeño en habilidades sociales en niños y niñas entre dos y tres años de edad. In: Acta Colombiana de Psicología. vol. 14(1), pp. 19-30. Bogotá: 2011.

WAGNER, A.; PREDEBON, J., et. al. Compartilhar tarefas? Papéis e funções de pai e mãe na família contemporânea. In: Psicologia: Teoria e Pesquisa. vol. 21(2), pp. 181-186. Brasília: Universidade de Brasília, 2005.

WHITTAKER, J. E. V.; HARDEN, B. J., et. al. Family risks and protective factors: Pathways to Early Head Start toddlers' social-emotional functioning. In: Early Childhood Research Quarterly. vol. 26, pp. 74 - 86. Ohio: 2011.

WEBER, L. N. D.; PRADO, P. M.; et. al. Identificação de Estilos Parentais: O ponto de Vista dos Pais e dos Filhos. In: Psicologia: Reflexão e Crítica. Pp. 323 331. Porto Alegre: UFRGS, 2004.

WOLFF, J. C.; OLLENDICK, T. H. The comorbidity of conduct problems and depression in childhood and adolescence. In: Clinical Child and Family Psychology Review. Vol. 9(3-4), pp. 201 - 220. 2006. 


\section{ANEXO I}

\section{UNIVERSIDADE DO ESTADO DO RIO DE JANEIRO - UERJ}

\section{PARECER CONSUBSTANCIADO DO CEP}

\section{DADOS DO PROJETO DE PESQUISA}

Titulo da Pesquisa: PREVALÊNCIA DOS COMPORTAMENTOS AGRESSIVOS EM CRIANÇAS ESCOLARES NA CIDADE DO RIO DE JANEIRO

Pesquisador: Juliane Callegaro Borsa

Area Temática:

Versão: 3

CAAE: 24367113.0 .0000 .5282

Instituição Proponente: FACULDADES CATOLICAS

Patrocinador Principal: Financiamento Proprio

\section{DADOS DO PARECER}

Número do Parecer: 576.669

Data da Relatoria: $27 / 03 / 2014$

Apresentação do Projeto:

O projeto foi apresentado por pesquisadora da PUC-Rio, do Programa de pos-graduação em Psicologia Clrnica que envolve crianças de escolas públicas e privadas no Rio de Janeiro. A pesquisadora e recemdoutora e tem especialidade na área. É um projeto nos moldes de uma pesquisa exclusivamente quantitativa.

\section{Objetivo da Pesquisa:}

O objetivo geral da pesquisa é investigar a prevalencia de comportamentos agressivos em uma amostra de crianças escolares de escolas públicas e privadas da cidade Rio de Janeiro.

Avaliação dos Riscos e Benefícios:

A pesquisa não envolve riscos diretos para as crianças mas pode gerar algum constrangimento aos pais no momento de responderem o questionário especffico sobre seus filhos.

Comentários e Considerações sobre a Pesquisa:

O trabalho está bem estruturado com referencial teơrico e metodologico adequado.

Considerações sobre os Termos de apresentação obrigatória:

A pesquisadora cumpriu o solicitado e justificou com clareza a razão de náo poder incluir a autorização das instituiçōes onde será feita a coleta de dados. O TCLE foi modificado conforme

Endereço: Rua São Francisco Xavier 524, BL E $3^{\circ}$ and. SI 3018

Bairro: Maracană

UF: R

CEP: $20.559-900$

E-mail: etica@uerj.br 


\section{UNIVERSIDADE DO ESTADO Platoformo DO RIO DE JANEIRO - UERJ}

Cantinuaçăo do Parecer: 576.669

solicitado.

\section{Recomendações:}

\section{Não Há.}

Conclusões ou Pendências e Lista de Inadequações:

Tendo em vista ocumprimento das solicitações, o projeto pode ser aprovado.

Situação do Parecer:

Aprovado

Necessita Apreciação da CONEP:

Nāo

Considerações Finais a critério do CEP:

Apos o cumprimento das exigencias ao parecer anterior, a COEP considerou o projeto aprovado.

Faz-se necessário apresentar Relatório Anual - previsto para março de 2015. Alem disso, a COEP deverá ser informada de fatos relevantes que alterem o curso normal do estudo, devendo o pesquisador apresentar justificativa, caso o projeto venha a ser interrompido e/ou os resultados não sejam publicados.




UNIVERSIDADE DO ESTADO

DO RIO DE JANEIRO - UERJ

Continuaçãáo do Parecer: 576.669

RIO DE JANEIRO, 01 de Abril de 2014

Assinador por:

Patricia Fernandes Campos de Moraes

(Coordenador)

Endereço: Rua Sāo Francisco Xavier 524, BL E $3^{\circ}$ and. SI 3018

Bairro: Maracanā

UF: RJ

CEP: $20.559-900$

Município: RIO DE JANEIRO

Telefone: (21)2334-2180 Fax: (21)2334-2180 E-mail: etica@uerj.br 


\section{ANEXO II \\ Carta de apresentação à escola e aos pais}

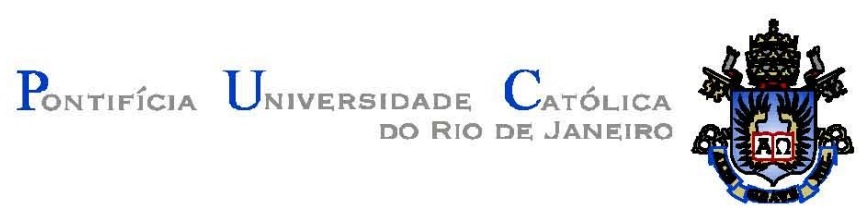

CARTA DE APRESENTAÇÃo

À Escola e aos Pais:

Vimos por meio desta, apresentar à escola e aos pais o Projeto de Pesquisa intitulado"PREVALÊNCIA DE COMPORTAMENTOS AGRESSIVOS EM CRIANÇAS ESCOLARES NA CIDADE DO RIO DE JANEIRO", de autoria da Dra. Juliane Callegaro Borsa, professora do Departamento de Psicologia da Pontifícia Universidade Católica do Rio de Janeiro - PUC-Rio.

Convidamos os(as) Sr.(as) a participar deste estudo que possui, dentre seus objetivos, investigar a prevalência de comportamentos agressivos em crianças de oito a 12 anos, estudantes de escolas públicas e privadas da cidade do Rio de Janeiro.

Desde já colocamo-nos à disposição para qualquer esclarecimento e agradecemos a sua disponibilidade em estar contribuindo para este estudo e para o desenvolvimento da ciência.

Atenciosamente:

\section{Pesquisadora}

Rio de Janeiro

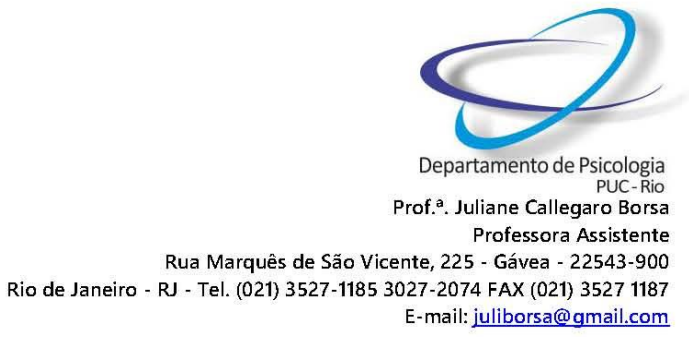




\title{
ANEXO III \\ Modelo carta de autorização para a escola
}

\author{
Pontifíicia Universidade Católica $_{\text {a }}$ \\ DO RIO DE JAINEIRO
}

CARTA DE AUTORIZAÇÃO PARA A ESCOLA

$\mathrm{Eu}$ em nome da

Escola

concordo em participar da pesquisa intitulada "Prevalência dos comportamentos agressivos em crianças escolares da cidade do Rio de Janeiro", de autoria da Dra. Juliane Callegaro Borsa, professora do Departamento de Psicologia da PUC-Rio.

Confirmo que recebi uma cópia do projeto de pesquisa e estou ciente dos objetivos e procedimentos propostos. Assim, autorizo a realização da coleta de dados nesta escola.

Concordo e assino abaixo:

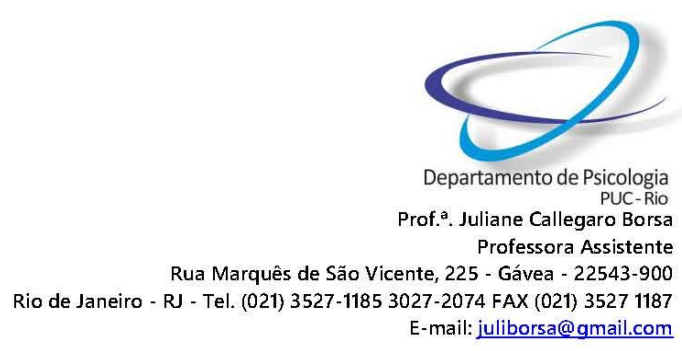




\section{ANEXO IV \\ Questionário biossociodemográfico}

\section{QUESTIONÁRIO BIOSSOCIODEMOGRÁFICO}

Cidade: Estado :

Localidade: ( ) Urbana ( ) Rural

Sexo: ( ) Feminino ( ) Masculino

Idade: anos

Qual é o estado civil do pai?
( ) Solteiro
( ) Casado/União Estável
( ) Viúvo
( ) Divorciado/Separado

Qual é o estado civil da mãe?
( ) Solteiro
( ) Casado/União Estável
( ) Viúvo
( ) Divorciado/Separado

Quantos filhos você tem?

Indique o sexo e a idade dos seus filhos (seguindo a ordem de nascimento, do mais velho para novo)

Masculino ( ) Feminino ( ) Idade:_ anos

Masculino ( ) Feminino ( ) Idade: anos

Masculino ( ) Feminino ( ) Idade: anos

Masculino ( ) Feminino ( ) Idade: anos

Masculino ( ) Feminino ( ) Idade:_ anos

Em que medida o pai é religioso?
( ) Nada
( ) Pouco
( ) Mais ou Menos
( ) Bastante
( ) Totalmente

Em que medida a mãe é religiosa?
( ) Nada
( ) Pouco
( ) Mais ou Menos
( ) Bastante
( ) Totalmente

Qual o grau de escolaridade do pai da criança?
( ) Ensino Fundamental Incompleto ( ) Ensino Fundamental Completo
( ) Ensino Médio Incompleto
( ) Ensino Médio Completo
( ) Ensino Superior Incompleto
( ) Ensino Superior Completo
( ) Pós-Graduação Incompleta
( ) Pós-Graduação Completa

Qual o grau de escolaridade da mãe da criança?
( ) Ensino Fundamental Incompleto ( ) Ensino Fundamental Completo
( ) Ensino Médio Incompleto
( ) Ensino Médio Completo
( ) Ensino Superior Incompleto
( ) Ensino Superior Completo
( ) Pós-Graduação Incompleta
( ) Pós-Graduação Completa 
O pai está trabalhando? ( ) Sim ( ) Não

Se sim, qual sua principal ocupação?

A mãe está trabalhando? ( ) Sim ( ) Não

Se sim, qual sua principal ocupação?

Qual é a renda mensal familiar?

( ) Até um salário mínimo (aproximadamente R\$ 550,00)

( ) De um a três salários mínimos (Entre R\$ 550,00 e R\$ 1.600,00)

( ) De três a seis salários mínimos (Entre $1.650,00$ e $3.300,00$ )

( ) De seis a nove salários mínimos (Entre 3.300,00 e R \$4.950,00)

( ) De nove a doze salários mínimos (Entre 4.950,00 e R\$ 6.600,00)

( ) Mais de doze salários mínimos (Mais de R\$6.600,00)

Instruções para as questões a seguir. Por favor, responda as próximas questões a respeito do seu fillho ou fillha que esteja cursando entre o $1^{\circ}$ e o $5^{\circ}$ ano do ensino fundamental. Caso você tenha mais de um(a) nesta situação, opte por responder sobre a criança mais velha.

De acordo com as instruções acima, indique o sexo e a idade do(a) filho(a) sobre quem você irá responder as questões a seguir.

Sexo: ( ) Masculino ( ) Feminino

Idade: anos

\begin{abstract}
Abaixo estão enumeradas algumas questões referentes ao seu filho(a) e ao contexto em que ele/ela está inserido/a. Marque com um $X$ se houve algumas dessas intercorrências:
\end{abstract}

A criança repetiu alguma série na escola?

( ) $\operatorname{Sim}$ ( ) Não

A criança apresenta dificuldade para aprender o conteúdo na escola?
( ) Muito Pouca
( ) Pouca
( ) Mais ou Menos
( ) Muita
( ) Bastante

A criança apresenta difículdade de se relacionar com os colegas (fazer amizades)?
( ) Muito Pouca
( ) Pouca
( ) Mais ou Menos
( ) Muita
( ) Bastante

A criança faz todas as refeições do dia adequadamente?
( ) Nunca
( ) Poucas vezes
( ) Às vezes
( ) Quase Sempre
( ) Sempre

Em relação à alimentação diária, a criança come:

( ) Muito Pouco ( ) Pouco ( ) Mais ou menos ( ) Muito ( ) Em excesso 
Quão comunicativa você considera a criança?
( ) Muito Pouco
( ) Pouco
( ) Mais ou menos
( ) Muito ( ) Em excesso

Quando a criança não está na escola, quem é responsável pelos seus cuidados na maior parte do tempo?
( ) Pais ( ) Avós
( ) Tios
( ) Irmãos
( ) Funcionários da casa
( ) Outros

Na rotina da criança, ela possui outras obrigações além de ir à escola?
( ) Nenhuma
( ) Prática de Esportes
( ) Aula de idiomas
( ) Reforço Escolar
( ) Aula de Música
( ) Outras

Quanto tempo de lazer a criança tem por dia?

O que ela costuma fazer neste tempo livre?

No dia-a-dia, a criança respeita as decisões do pai?

( ) Nunca ( ) Poucas vezes ( ) Às vezes ( ) Quase Sempre ( ) Sempre

No dia-a-dia, a criança respeita as decisões da mãe?

( ) Nunca ( ) Poucas vezes ( ) Às vezes ( ) Quase Sempre ( ) Sempre

Com que frequência a escola se queixa da criança por desrespeitar o(a) professor(a)? ( ) Nunca ( ) Poucas vezes ( ) Às vezes ( ) Quase Sempre ( ) Sempre

Como você avalia a saúde física da criança?
( ) Muito Boa
( ) Boa
( ) Mais ou menos
( ) Ruim
( ) Muito Ruim

Como você avalia a saúde mental da criança?
( ) Muito Boa
( ) Boa
( ) Mais ou menos
( ) Ruim
( ) Muito Ruim

A criança está em tratamento neurológico?

( ) $\operatorname{Sim}$ ( ) Não

A criança já fez atendimento psicológico?

( ) $\operatorname{Sim}($ ) Não

As questões a seguir referem-se à sua família. Para cada pergunta, marque um $\mathrm{X}$ na opção que você julgar mais adequada.

Quais são as pessoas da família que residem na mesma casa da criança? (Pode marcar mais de uma opção)
( ) Pai ( ) Mãe
( ) Padrasto
( ) Madrasta
( ) Irmãos
( ) Avós ( ) Outros

Houve mudança significativa na condição financeira da família?

( ) $\operatorname{Sim}$ ( ) Não 
Se sim, há quanto tempo?

Houve separação dos pais?

( ) Sim ( ) Não

Se sim, há quanto tempo?

Como você avalia a saúde física do pai da criança?
( ) Muito Boa
( ) Boa
( ) Mais ou menos
( ) Ruim
( ) Muito Ruim

Como você avalia a saúde mental do pai da criança?
( ) Muito Boa
( ) Boa
( ) Mais ou menos
( ) Ruim
( ) Muito Ruim

Como você avalia a saúde física mãe da criança?
( ) Muito Boa
( ) Boa
( ) Mais ou menos
( ) Ruim
( ) Muito Ruim

Como você avalia a saúde mental da mãe da criança?
( ) Muito Boa
( ) Boa
( ) Mais ou menos
( ) Ruim
( ) Muito Ruim

Houve eventos difíceis na sua familia nos últimos 12 meses?

( ) Muito Poucos ( ) Poucos ( ) Mais ou menos ( ) Muitos ( ) Em excesso

Houve eventos felizes na sua família nos últimos 12 meses?

( ) Muito Poucos ( ) Poucos ( ) Mais ou menos ( ) Muitos ( ) Em excesso 


\section{ANEXO V \\ Child Behavior Checklist - CBLC 6/18}

Child Behavior Checklist - CBCL 6/18

Inventário dos Comportamentos de CriançAs e Adolescentes entre 6 e 18 anos (CBCL)

NOME COMPLETO DA CRIANÇA/Adolescente:

ID (para uso exclusivo

\begin{tabular}{|c|c|c|c|}
\hline & L & RAGA & \multirow{2}{*}{$\begin{array}{l}\text { TIPO DE TRABALHO DOS PAIS, mesmo que não estejam } \\
\text { trabalhando no momento. (Por favor, seja especifico - por } \\
\text { exemplo: mecônico de automóveis, professor(a) de ensino } \\
\text { médio, dona de casa, operário, vendedor de sapato, sargento do } \\
\text { exército). } \\
\text { TIPO OE TRABALHO DO PAI: }\end{array}$} \\
\hline ATAA DE HOJE: & & & \\
\hline RIIE ESCOLAR: & \multirow{2}{*}{\multicolumn{2}{|c|}{$\begin{array}{l}\text { Por favor, responda todos os itens de acordo } \\
\text { com o modo como você vê o } \\
\text { comportamento de seu/sua filho(a), mesmo } \\
\text { que outras pessoas possam não concordar. } \\
\text { Esteja a vontade para escrever quaisquer } \\
\text { comentários adicionais abaixo de cada } \\
\text { questão e no espaço livre da página }-2 . \\
\text { CERTIFIQUE-SE DE RESPONDER TODOS Os ITENS. }\end{array}$}} & TIPO DE TRABALHO DO PAI:- \\
\hline & & & \\
\hline
\end{tabular}

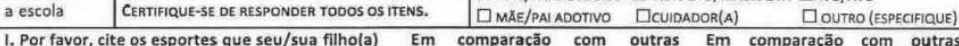
mais gosta de praticar. Por exemplo: nataç̃o, crianças/adolescentes da mesma crianģ futebol, andar de patins ou skate, andar de idade, quanto tempo é dedicado a idade, o desempenho dele(a) em bicicleta etc.
cada um?

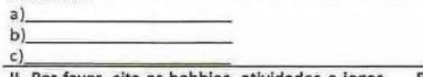
cada um desses esportes é:
Menos Igual Mais Não sei Pior Igual Melhor Não se

II. Por favor, cite os hobbles, atividades e jogos favoritos do seu/sua filho(a) que não sejam tocar violão, desenhar, soltar pipa, pular corda, brincar de boneca, brincar de carrinho, ler. cantar, usar o computador, jogar video-game. (Nảo incluir ouvir rádio ou ver televisåo) $\square$ nenhum Menos Igual Mais Nảo sei

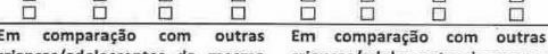
crianças/adolescentes da mesma idade, quanto tempo é dedicado a idade, o desempenho dele(a) em

a)

c) clubes, times ou grupos aos quais seu/sua filho(a) pertence. Por exemplo: turma de amigos etc.

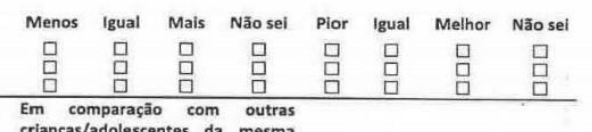
crianças/adolescentes da mesma idade, como é a participação Menor Igual Maior Năosei



V. Por favor, cite quaisquer trabalhos ou tarefas Em comparação com outras que seu/sua filho(a) tenha. Por exemplo: office- crianças/adolescentes da mesma louça; tomar conta das crianças; fazer a cama etc. (incluir tanto trabalhos pagos como não pagos). $\square$ nenhum dele(a) em cada um?

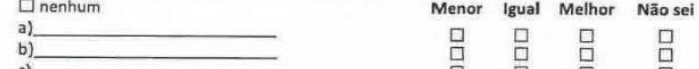

CERTIFIQUE-SE DE QUE RESPONDEU TODOS OS PRÓXIMA PIGINA

c) COPYRIGHT 2001 T. ACHENBACH \& RESCORLA. REPRODUCED UNDER LICENSE \#201-12-04-06. PrOIBIDA A REPRODUÇ̄̃o NÃO AUTORIZZADA. Traduçăo: Silvares, E. F. M.; Rocha, M. M. \& Equipe Projeto Enurese (2007). Versão brasileira não publicada do inventário "Child Behavior Checklist for ages 6-18" (Achenbach \& Rescorla, 2001).

Proft Dra. Edwiges Ferreira de Mattos Silvares

Instituto de Psicologia - Universidade de Såo Paul

Av. Prof. Melo Moraes, 1721/ Săo Paulo - SP

effemsiliveusp, be 
POR FAVOR, CERTIFIQUE-SE DE RESPONDER TODOS OS ITENS.



2. O seu filho(a) freqüenta alguma escola, aula de reforço ou estabelecimento de ensino especial? $\square$ Não $\square$ Sim - que tipo?

3. O seu filho(a) repetiu algum ano? $\square$ Não $\square$ Sim - Cite as séries que repetiu e as razões.

4. O seu filho(a) teve algum problema no desempenho escolar ou outro tipo de problema na escola? $\square$ Não $\square$

Sim - Descreva-o, por favor:

Quando esses problemas começaram?

Os problemas mencionados já foram resolvidos? $\square$ Não $\square$ Sim - quando? O seu filho(a) tem alguma doença ou deficiência (fisica ou mental)? $\square$ Não $\square$ Sim - Descreva-a, por favor:

Qual é a sua maior preocupação em relação ao seu filho(a)?

Por favor, descreva os aspectos mais positivos do seu filho(a).

POR FAVOR, CERTIFIQUE-SE DE QUE RESPONDEU TODOS OS ITENS. 
POR FAVOR, CERTIFIQUE-SE DE RESPONDER TODOS OS ITENS

Logo abaixo, você encontrará uma lista de afirmações que descrevem crianças/adolescenter. Para cada afirmação que descreva seu/sua filho(a) neste momento ou nos últimos seis meses, trace um circulo à volta do 2 se a afirmação é muito verdadeira ou freqüentemente verdadeira em relação ao seu filho(a). Trace um circulo à volta do 1 se a afirmação é um pouco verdadeira ou algumas vezes verdadeira em relação ao seu filho(a). Se a afirmação não é verdadeira em relação ao seu filho(a), trace um circulo à volta do 0 . Por favor, responda a todas as afirmaçōes o melhor que possa, mesmo que algumas não pareçam aplicáveis ao seu filho(a).

\begin{tabular}{|c|c|c|c|c|c|c|c|c|}
\hline \multirow{2}{*}{\multicolumn{4}{|c|}{$\begin{array}{l}0=\text { =NÃO } E \text { VERDADEIRA } \\
\text { (TANTO QUANTO SABE) }\end{array}$}} & \multicolumn{4}{|c|}{$1=$ =UM POUCO VERDADEIRA OU } & \multirow{2}{*}{$\begin{array}{l}\mathbf{2}=\text { MUITO VERDADEIRA OU } \\
\text { FREQUUENTEMENTE VERDADEIRA }\end{array}$} \\
\hline & & & & \multicolumn{4}{|c|}{ ALGUMAS VEZES VERDADEIRA } & \\
\hline \multirow{2}{*}{\multicolumn{2}{|c|}{01}} & & \multirow{2}{*}{\multicolumn{2}{|c|}{$\begin{array}{l}\text { 1. Comporta-se de maneira muito infantil para a } \\
\text { sua idade }\end{array}$}} & \multicolumn{4}{|c|}{$\begin{array}{llll}0 & 1 & 2 & 32 . \text { Acha que deve ser perfeito(a) }\end{array}$} \\
\hline & & & & & & 12 & 33. $\mathrm{AC}$ & reclama que ninguém gosta dele(a) \\
\hline \multirow{2}{*}{\multicolumn{2}{|c|}{01}} & \multirow[t]{2}{*}{2} & \multirow{2}{*}{\multicolumn{2}{|c|}{$\begin{array}{l}\text { 2. Toma bebida alcoólica sem a aprovação dos } \\
\text { pais (descreva) }\end{array}$}} & \multirow{3}{*}{$\begin{array}{lll}0 & 1 \\
0 & 1 \\
0 & 1 \\
0 & 1\end{array}$} & \multirow[t]{3}{*}{12} & \multirow{2}{*}{\multicolumn{2}{|c|}{$\begin{array}{l}\text { 34. Acha que os outros o(a) perseguem } \\
\text { 35. Sente-se sem valor ou inferior } \\
\text { 36. Machuca-se com freqüência, tem tendência a } \\
\text { sofrer acidentes }\end{array}$}} \\
\hline & & & & & & & & \\
\hline $\begin{array}{l}0 \\
0\end{array}$ & 1 & 2 & \multicolumn{2}{|l|}{ 3. Discute muito } & & & \multicolumn{2}{|c|}{ 37. Mete-se em muitas brigas } \\
\hline $\begin{array}{l}0 \\
0\end{array}$ & 1 & $\begin{array}{l}2 \\
2\end{array}$ & \multicolumn{2}{|c|}{ 4. Não termina as coisas que começou } & & 12 & \multicolumn{2}{|c|}{ 38. É alvo de muitas provocações } \\
\hline $\begin{array}{l}0 \\
0\end{array}$ & $\begin{array}{l}1 \\
1\end{array}$ & $\begin{array}{l}2 \\
2\end{array}$ & \multicolumn{2}{|c|}{ 6. Faz cocô na calça ou fora do vaso sanitário } & 0 & $\begin{array}{ll}1 & 2 \\
1 & 2\end{array}$ & \multirow{2}{*}{\multicolumn{2}{|c|}{$\begin{array}{l}\text { 39. Anda com pessoas que se metem em } \\
\text { encrencas }\end{array}$}} \\
\hline 0 & 1 & 2 & \multicolumn{2}{|c|}{ 7. É convencido(a), conta vantagem } & & & & \\
\hline 0 & 1 & 2 & $\begin{array}{l}\text { 8. Não consegue conc } \\
\text { ficar atento(a) muito }\end{array}$ & consegue & 0 & \multirow[t]{2}{*}{12} & $\begin{array}{l}\text { 40. Es } \\
\text { (desc }\end{array}$ & sons ou vozes que não existem \\
\hline 0 & 1 & 2 & 9. Não consegue tir. & entos da & & & & \\
\hline & & & cabeça; ob: & & & 12 & 41. É & (a), ou age sem pensar \\
\hline 0 & 1 & 2 & 10. Não consegue & & & & $\begin{array}{l}42 . P \\
\text { com }\end{array}$ & de outros \\
\hline & & & irrequ & & & 12 & 43. 1 & engana os outros \\
\hline 0 & 1 & 2 & 11. Agarra-se aos adu & o dependente & 0 & 12 & 44. $R$ & \\
\hline 0 & 1 & 2 & 12. Reclama & & 0 & 12 & 45. É & a) ou tenso(a) \\
\hline 0 & 1 & 2 & 13. Fica confuso(a) ou & & 0 & 12 & 46. $T$ & rvosos ou tiques \\
\hline 0 & 1 & 2 & 14. Chora & & & & & \\
\hline 0 & 1 & 2 & 15. É cruel com ani & & & & & \\
\hline 0 & 1 & 2 & 16. Manifesta cr & & 0 & 12 & 47. $\mathrm{T}$ & elos \\
\hline 0 & 1 & 2 & $\begin{array}{l}\text { malda } \\
\text { 17. So }\end{array}$ & eus & 0 & 12 & & $\begin{array}{l}\text { crianças ou adolescentes não } \\
\text { a) }\end{array}$ \\
\hline & & & pensamentos & & & 12 & 49. & de ventre, intestino preso \\
\hline 0 & 1 & 2 & 18. Machuca-se de & tou & & 12 & 50. & edroso(a) ou ansioso(a) \\
\hline & & & suicid & & & 12 & 51. & \\
\hline 0 & 1 & 2 & 19. Exige qu & iele(a) & & 12 & 52. & (a) \\
\hline 0 & 1 & 2 & 20. Destrói s & & 0 & 12 & 53. & \\
\hline 0 & 1 & 2 & 21. Destrói coisas de & e outros & 0 & 12 & 54. $\mathrm{S}$ & ansado(a) demais sem motivo \\
\hline 0 & 1 & 2 & 22. É desobediente en & & 0 & 12 & 55. Es & na do peso \\
\hline 0 & 1 & 2 & 23. É desobediente $r$ & & & & 56. $\mathrm{T}$ & lemas físicos sem causa conhecida \\
\hline 0 & 1 & 2 & 24. Não come bem & & & & & ista médico: \\
\hline 0 & 1 & 2 & $\begin{array}{l}\text { 25. Não se dá bem co } \\
\text { adolescentes }\end{array}$ & as ou & & $\begin{array}{ll}1 & 2 \\
1 & 2\end{array}$ & $\begin{array}{l}\text { a) } \mathrm{Do} \\
\text { b) } \mathrm{Dc}\end{array}$ & $\begin{array}{l}\text { eto de cabeça ou de estômago) } \\
\text { abeça }\end{array}$ \\
\hline 0 & 1 & 2 & 26. Não parece sentir- & epois de se & 0 & 12 & c) Náb & jôos \\
\hline 0 & 1 & 2 & $\begin{array}{l}\text { comportar mal } \\
\text { 27. Sente ciúme com }\end{array}$ & & & 12 & $\begin{array}{l}\text { d) Pro } \\
\text { corri }\end{array}$ & $\begin{array}{l}\text { s com os olhos (que não são } \\
\text { om o uso de óculos) (descreva): }\end{array}$ \\
\hline 0 & 1 & 2 & $\begin{array}{l}\text { 28. Desrespeita as reg } \\
\text { em outros lugares }\end{array}$ & escola ou & & & & \\
\hline 0 & 1 & 2 & $\begin{array}{l}\text { 29. Tem medo de cert } \\
\text { lugares, sem incluir a }\end{array}$ & $\begin{array}{l}\text { açōes ou } \\
\text { a): }\end{array}$ & & $\begin{array}{ll}1 & 2 \\
1 & 2 \\
1 & 2\end{array}$ & $\begin{array}{l}\text { e) As } \\
\text { f) } \mathrm{Dc}\end{array}$ & $\begin{array}{l}\text { ou outros problemas de pele } \\
\text { tômago ou de barriga }\end{array}$ \\
\hline & 1 & 2 & 30. Tem medo de ir & & & $\begin{array}{ll}1 & 2 \\
1 & 2)\end{array}$ & & lescreva): \\
\hline 0 & 1 & 2 & $\begin{array}{l}\text { 31. Tem medo de pe } \\
\text { má }\end{array}$ & uma coisa & & & & \\
\hline
\end{tabular}




\begin{tabular}{|c|c|c|c|c|c|c|}
\hline \multicolumn{7}{|c|}{ POR FAVOR, CERTIFIQUE-SE DE RESPONDER TODOS OS ITENS. } \\
\hline & \multirow{2}{*}{\multicolumn{2}{|c|}{$\begin{array}{l}0=\text { NÃO } E \text { VERDADEIRA } \\
\text { (TANTO QUANTO SABE) }\end{array}$}} & \multirow{2}{*}{\multicolumn{3}{|c|}{$\begin{array}{l}1 \text { =UM POUCO VERDADEIRA OU } \\
\text { ALGUMAS VEZES VERDADEIRA }\end{array}$}} & \multirow{2}{*}{$\begin{array}{l}2 \text { = MUITO VERDADEIRA OU } \\
\text { FREQÜENTEMENTE VERDADEIRA }\end{array}$} \\
\hline & & & & & & \\
\hline & 12 & \multirow{3}{*}{\multicolumn{2}{|c|}{$\begin{array}{l}\text { 57. Ataca fisicamente as pessoas } \\
\text { 58. Cutuca o nariz, a pele ou outras partes } \\
\text { do corpo (descreva) }\end{array}$}} & $\begin{array}{ll}\text { ES VERDADEIR. } \\
0128\end{array}$ & \multirow{2}{*}{\multicolumn{2}{|c|}{$\begin{array}{l}\text { 84. Tem comportamento estranho } \\
\text { (descreva): }\end{array}$}} \\
\hline 01 & 12 & & & \multirow[b]{2}{*}{012} & & a): \\
\hline & & $\overline{59 . \text { Mexe nas partes íntimas em público }}$ & & & \multicolumn{2}{|c|}{ 85. Tem idéias estranhas (descreva): } \\
\hline 01 & & \multirow{2}{*}{\multicolumn{2}{|c|}{$\begin{array}{l}\text { 60. Mexe demais nas partes intimas } \\
61 . \text { Os seus trabalhos escolares são fracos }\end{array}$}} & \multirow{2}{*}{012} & \multicolumn{2}{|c|}{ 86. Teimoso(a), mal humorado(a) ou fácil } \\
\hline 01 & 12 & & & & \multicolumn{2}{|c|}{$\begin{array}{l}\text { 86. Teimoso(a), mal humorado(a) ou fácil } \\
\text { de irritar }\end{array}$} \\
\hline & & \multicolumn{2}{|c|}{$\begin{array}{l}\text { 61. Os seus trabalhos escolares são fracos } \\
\text { 62. Desastrado(a) ou tem falta de } \\
\text { coordenação }\end{array}$} & 012 & \multicolumn{2}{|c|}{$\begin{array}{l}\text { 87. Tem mudanças repentinas de humor ou } \\
\text { de sentimentos }\end{array}$} \\
\hline & & \multicolumn{2}{|c|}{$\begin{array}{l}\text { coordenação } \\
\text { 63. Prefere estar com crianças/adolescentes }\end{array}$} & $\begin{array}{lll}0 & 1 & 2 \\
0 & 1 & 2\end{array}$ & \multicolumn{2}{|c|}{ 88. Fica facilmente emburrado(a) } \\
\hline & & \multicolumn{2}{|c|}{$\begin{array}{l}\text { 64. Prefere estar com crianças/adolescentes } \\
\text { mais novos }\end{array}$} & \multirow{2}{*}{$\begin{array}{llll}0 & 1 & 2 \\
0 & 1 & 2 & \\
0 & 1 & 2 & \end{array}$} & \multicolumn{2}{|c|}{$\begin{array}{l}\text { 90. Xinga ou fala palavrões } \\
\text { 91. Fala que vai se matar }\end{array}$} \\
\hline 01 & 12 & \multirow{2}{*}{\multicolumn{2}{|c|}{$\begin{array}{l}\text { 65. Recusa-se a falar } \\
\text { 66. Repete as mesmas ações várias vezes } \\
\text { seguidas, compulsões (descreva): }\end{array}$}} & & \multicolumn{2}{|c|}{$\begin{array}{l}\text { 91. Fala que val se matar } \\
\text { 92. Fala ou anda dormindo (descreva): }\end{array}$} \\
\hline 01 & 12 & & & $0 \begin{array}{lll}0 & 1 & 2\end{array}$ & \multicolumn{2}{|c|}{ 93. Fala demais } \\
\hline & & & & $\begin{array}{lll}0 & 1 & 2\end{array}$ & 94. $\operatorname{Pro}$ & oca muito \\
\hline & & & & 012 & 95. Faz & jirra ou é esquentado(a) \\
\hline & 2 & 67. Foge de casa & & $\begin{array}{llll}0 & 1 & 2\end{array}$ & 96. Per & a demais em sexo \\
\hline 01 & 12 & 68. Grita muito & & $\begin{array}{llll}0 & 1 & 2\end{array}$ & 97. Am & as pessoas \\
\hline & & 2 69. Reservado(a), & as coisas para si & 012 & 98. Chi & o dedo \\
\hline & & $\begin{array}{l}\text { mesmo(a) } \\
70 \text {. Vê coisas que nã }\end{array}$ & m (descreva): & 012 & $\begin{array}{l}\text { 99. Fur } \\
\text { tabaco }\end{array}$ & cigarro, masca fumo ou cheira \\
\hline & & & & 012 & 100. Te & n problemas com sono (descreva): \\
\hline 01 & 12 & 71. Mostra-se pou & & & & \\
\hline & & $\begin{array}{l}\text { facilmente envergonł } \\
72 . \text { Pöe fogo nas cois }\end{array}$ & & 012 & $\begin{array}{l}\text { 101. Fa } \\
\text { aula }\end{array}$ & à escola sem permissão, mata \\
\hline 01 & & 73.Tem problemas s & descreva): & 012 & $\begin{array}{l}\text { 102. Pc } \\
\text { lentos }\end{array}$ & $\begin{array}{l}\text { to ativo(a), seus movimentos são } \\
\text { tem falta de energia }\end{array}$ \\
\hline & 12 & 74. Gosta de se exibi & palhacadas & $\begin{array}{llll}0 & 1 & 2 \\
0 & 1 & 2\end{array}$ & $\begin{array}{l}\text { 103. In } \\
\text { 104. } B a\end{array}$ & $\begin{array}{l}\text { triste ou deprimido(a) } \\
\text { ento(a) demais }\end{array}$ \\
\hline 01 & 12 & 75. Muito acanhado ( & mido(a) & $\begin{array}{lll}0 & 1 & 2 \\
0 & 1 & 2\end{array}$ & 105. U & rogas sem fins medicinais (não \\
\hline 01 & & $\begin{array}{l}\text { 76. Dorme menos qu } \\
\text { crianças ou adolescer }\end{array}$ & oria das & & inclui & ol ou tabaco) (descreva): \\
\hline & 12 & 77. Dorme mais que & as crianças & 012 & $106 . \mathrm{Cc}$ & nete atos de vandalismo \\
\hline & & ou adolescentes dura & ou durante & $\begin{array}{lll}0 & 1 & 2\end{array}$ & 107. Fa & ki na calça \\
\hline & & a noite (descreva): & & $\mid \begin{array}{lll}0 & 1 & 2 \\
0 & 1 & 2\end{array}$ & $\begin{array}{l}\text { 108. Fe } \\
\text { 109. Cl }\end{array}$ & $\begin{array}{l}\text { kixi na cama } \\
\text { aminga }\end{array}$ \\
\hline & 12 & 78. Desatento(a) ou & e facilmente & $\begin{array}{llll}0 & 1 & 2\end{array}$ & 110. G & staria de ser do sexo oposto \\
\hline & & 79. Ten & & $\begin{array}{llll}0 & 1 & 2\end{array}$ & $\begin{array}{l}\text { 111. Is } \\
\text { outros }\end{array}$ & -se, não se relaciona com os \\
\hline & & & & 012 & 112. $\mathrm{Pr}$ & ocupa-se muito \\
\hline & 12 & 80. Fica com o olhar & & & 113. & vor, escreva outros problemas \\
\hline 01 & $\begin{array}{ll}1 & 2 \\
1 & 2\end{array}$ & $\begin{array}{l}\text { 81. Rouba em casa } \\
\text { 82. Rouba fora de ca }\end{array}$ & & & & nados na lista acima: \\
\hline & 12 & 83. Junta muitas cois & precisa & $0 \begin{array}{lll}0 & 1 & 2\end{array}$ & & \\
\hline & & (d & & $\begin{array}{lll}0 & 1 & 2 \\
0 & 1 & 2 \\
\end{array}$ & & \\
\hline
\end{tabular}




\section{ANEXO VI \\ Inventário do Clima Familiar (ICF)}

Inventário do Clima Familiar (ICF)

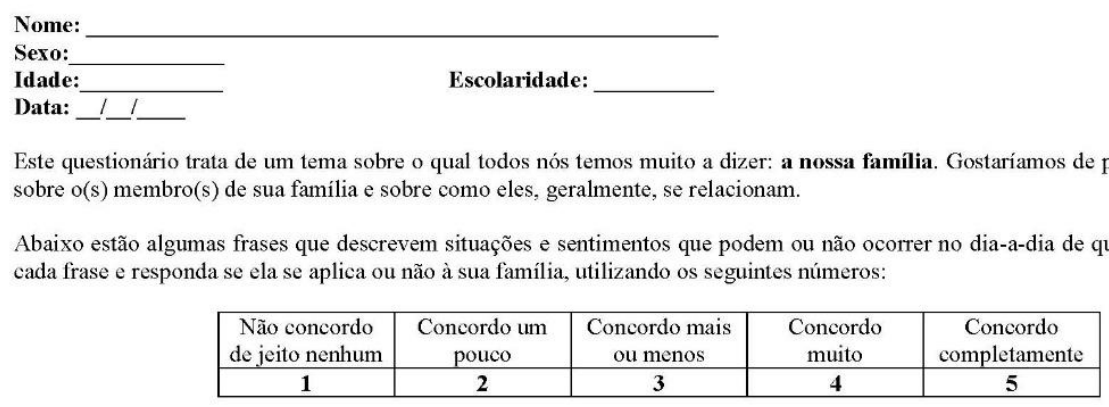

Lembre-se de que não existem respostas certas ou erradas. Nós só desejamos saber como as coisas têm estado em sua família ultimamente.

Em minha família...

\begin{tabular}{|c|c|c|c|}
\hline $\begin{array}{l}\text { De jeito } \\
\text { nenhum }\end{array}$ & Pouco & $\begin{array}{c}\text { Mais ou } \\
\text { menos }\end{array}$ & Muito \\
\hline
\end{tabular}




\begin{tabular}{|c|c|c|c|c|c|}
\hline $\begin{array}{l}\text { 1. Procuramos ajudar as pessoas da nossa família quando } \\
\text { percebemos que estão com problemas. }\end{array}$ & 1 & 2 & 3 & 4 & 5 \\
\hline 2. As proibições são constantes. & 1 & 2 & 3 & 4 & 5 \\
\hline 3. Uns mandam e outros obedecem. & 1 & 2 & 3 & 4 & 5 \\
\hline 4. As pessoas zombam umas das outras. & 1 & 2 & 3 & 4 & 5 \\
\hline 5. Briga-se por qualquer coisa. & 1 & 2 & 3 & 4 & 5 \\
\hline $\begin{array}{l}\text { 6. Algumas pessoas deixam de fazer as suas coisas para auxiliar as } \\
\text { outras pessoas da familia. }\end{array}$ & 1 & 2 & 3 & 4 & 5 \\
\hline $\begin{array}{l}\text { 7. Não importa a vontade da maioria, a decisão final é sempre da } \\
\text { mesma pessoa. }\end{array}$ & 1 & 2 & 3 & 4 & 5 \\
\hline 8. As pessoas irritam umas às outras. & 1 & 2 & 3 & 4 & 5 \\
\hline 9. As pessoas gostam de passear e de fazer coisas juntas. & 1 & 2 & 3 & 4 & 5 \\
\hline 10. As pessoas resolvem os problemas brigando. & 1 & 2 & 3 & 4 & 5 \\
\hline 11. As pessoas criticam umas às outras freqüentemente. & 1 & 2 & 3 & 4 & 5 \\
\hline 12. Resolver problemas significa discussão e brigas. & 1 & 2 & 3 & 4 & 5 \\
\hline $\begin{array}{l}\text { 13. As pessoas tentam ajudar umas às outras quando as coisas não } \\
\text { vão bem. }\end{array}$ & 1 & 2 & 3 & 4 & 5 \\
\hline 14. As pessoas gostam umas das outras. & 1 & 2 & 3 & 4 & 5 \\
\hline 15. Sinto que existe união entre os membros. & 1 & 2 & 3 & 4 & 5 \\
\hline 16. Os mais velhos mandam mais. & 1 & 2 & 3 & 4 & 5 \\
\hline
\end{tabular}

\begin{tabular}{|llllll|}
\hline 17. As pessoas se sentem próximas umas das outras. & 1 & 2 & 3 & 4 & 5 \\
\hline 18. O(s) filho(s) têm pouco poder nas decisões familiares. & 1 & 2 & 3 & 4 & 5 \\
\hline $\begin{array}{l}\text { 19. Temos prazer e alegria em passar o tempo juntos. } \\
\text { 20. Algumas pessoas resolvem os problemas de maneira autoritária }\end{array}$ & 1 & 2 & 3 & 4 & 5 \\
\hline $\begin{array}{l}\text { 21. Ajudamos financeiramente uns aos outros. } \\
\begin{array}{l}\text { 22. As pessoas me ajudam a fazer as coisas quando não tenho } \\
\text { tempo. }\end{array}\end{array}$ & 1 & 2 & 3 & 4 & 5 \\
\hline
\end{tabular}

